\title{
MOSCAS-DAS-FRUTAS EM CITROS: DENSIDADE DE ARMADILHAS PARA MONITORAMENTO, EFEITO DO PH NA ATRAÇÃO E DETERMINAÇÃO DO NÍVEL DE CONTROLE
}

\section{Paulo Eduardo Branco Paiva}

Dissertação apresentada à Escola Superior de Agricultura "Luiz de Queiroz", Universidade de São Paulo, para obtenção do título de Mestre em Ciências, Área de Concentração: Entomologia.

\author{
P I R A C I C A B A \\ Estado de São Paulo - Brasil \\ Maio - 2004
}




\title{
MOSCAS-DAS-FRUTAS EM CITROS: DENSIDADE DE ARMADILHAS PARA MONITORAMENTO, EFEITO DO PH NA ATRAÇÃO E DETERMINAÇÃO DO NÍVEL DE CONTROLE
}

\author{
PaUlo Eduardo Branco Paiva \\ Engenheiro Agrônomo
}

Orientador: Prof. Dr. JOSÉ ROBERTO POSTALI PARRA

\begin{abstract}
Dissertação apresentada à Escola Superior de Agricultura "Luiz de Queiroz", Universidade de São Paulo, para obtenção do título de Mestre em Ciências, Área de Concentração: Entomologia.
\end{abstract}

\author{
P I R A C I C A B A \\ Estado de São Paulo - Brasil \\ Maio - 2004
}




\section{Dados Internacionais de Catalogação na Publicação (CIP) DIVISÃO DE BIBLIOTECA E DOCUMENTAÇÃO - ESALQ/USP}

Paiva, Paulo Eduardo Branco

Moscas-das-frutas em citros: densidade de armadilhas para monitoramento, efeito do pH na atração e determinação do nível de controle / Paulo Eduardo Branco Paiva. - Piracicaba, 2004.

48 p. : il.

Dissertação (mestrado) - - Escola Superior de Agricultura Luiz de Queiroz, 2004.

Bibliografia.

1. Armadilha para inseto 2. Atrativo para inseto 3. Fruta cítrica 4. Laranja 5. Monitoramento 6. Mosca-das-frutas 7. pH I. Título

CDD 632.774

"Permitida a cópia total ou parcial deste documento, desde que citada a fonte - O autor" 
Dedico este trabalho

a minha esposa Sileuza,

aos meus pais Aparecida e Paulo Paiva, aos meus avós Assumpta e José Branco,

e a minha irmã Cristiane. 


\section{AGRADECIMENTOS}

Em especial ao Prof. Dr. José Roberto Postali Parra pela oportunidade e pela orientação.

Aos Professores do Setor de Entomologia, do Departamento de Entomologia, Fitopatologia e Zoologia Agrícola da Escola Superior de Agricultura "Luiz de Queiroz" (ESALQ), da Universidade de São Paulo (USP), pelos ensinamentos.

Ao Consultor Eng. Agr. Antonio Celso Sanches (Maneco), do GCONCl, pelo incentivo e grande amizade.

Ao Biólogo Fábio Di Giorgi e a Coinbra-Frutesp Agropecuária Ltda. pelo incentivo, oportunidade e apoio.

Ao citricultor Raphael Juliano pelo apoio ao trabalho com moscas-das-frutas.

Ao Prof. Dr. José Maurício S. Bento pelas sugestões e críticas.

Ao Eng Agr. MSc. Miguel F. de Souza Filho pela identificação das espécies de Anastrepha.

Ao Biólogo Pedro Carlos Strikis pela identificação das espécies de lonqueídeos. 
Aos amigos Júnior, Alessandra e Bruna pela hospedagem e amizade.

A todos os amigos do PPG em Entomologia, pelo convívio, amizade e discussões entomológicas.

E a todos os outros que contribuíram para a realização deste trabalho. 


\section{SUMÁRIO}

Página

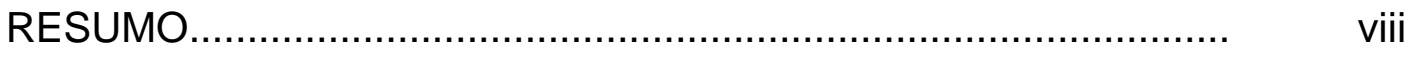

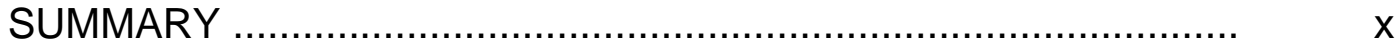

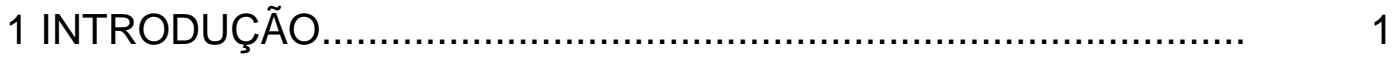

2 REVISÃO DE LITERATURA....................................... 3

2.1 Espécies de moscas-das-frutas em citros............................ 4

2.2. Atrativos para monitoramento.................................... 5

2.3 Densidade de armadilhas para monitoramento..................... 7

2.4 Relação entre captura de moscas-das-frutas e dano................ 9

3 MATERIAL E MÉTODOS............................................. 10

3.1 Efeito do $\mathrm{pH}$ e do tempo de permanência do atrativo na captura de espécies de moscas-das-frutas

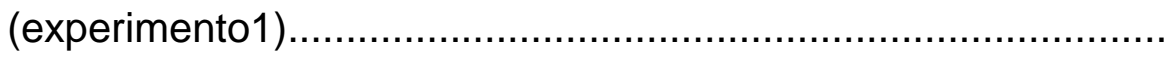

3.2 Determinação da densidade de armadilhas para monitoramento e relação entre moscas-das-frutas capturadas e frutos danificados, em laranja de maturação precoce

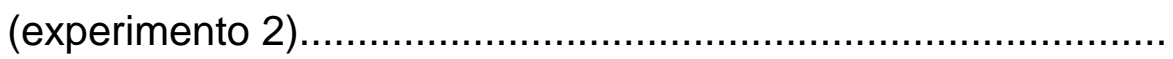

3.3 Determinação da densidade de armadilhas para monitoramento e relação entre moscas-das-frutas capturadas e frutos danificados, em laranja de maturação tardia (experimento 3) 
4 RESULTADOS E DISCUSSÃO............................................... 18

4.1 Efeito do pH e do tempo de permanência do atrativo no campo na captura de Ceratitis capitata................................................. 18

4.2 Espécies e proporção sexual de captura.................................. 23

4.3 Efeito da densidade de armadilhas na captura de moscas-dasfrutas em laranja precoce................................................... $\quad 25$

4.4 Efeito da densidade de armadilhas na captura de moscas-dasfrutas em laranja tardia........................................................ 28

4.5 Relação entre captura de moscas-das-frutas e o dano............... $\quad 30$

4.6 Dano causado pela mosca-das-frutas C. capitata em laranja



4.7 Dano causado por moscas-das-frutas em laranja tardia............. $\quad 40$ 5 CONCLUSÕES..................................................................... 42

REFERÊNCIAS BIBLIOGRÁFICAS.............................................. 43 


\title{
MOSCAS-DAS-FRUTAS EM CITROS: DENSIDADE DE ARMADILHAS PARA MONITORAMENTO, EFEITO DO PH NA ATRAÇÃO E DETERMINAÇÃO DO NIVEL DE CONTROLE
}

\author{
Autor: PAULO EDUARDO BRANCO PAIVA \\ Orientador: Prof. Dr. JOSÉ ROBERTO POSTALI PARRA
}

\section{RESUMO}

Este trabalho teve por objetivos: avaliar o efeito do $\mathrm{pH}$ inicial e o tempo de permanência no campo do atrativo alimentar Milhocina ${ }^{\circledR}$ com o conservante bórax (tetraborato de sódio) na captura de moscas-das-frutas em armadilhas do tipo McPhail; estudar densidades de armadilhas para monitoramento de moscas-das-frutas e determinar um nível de dano e de controle em cultura de laranja. Foram realizados três experimentos de campo, o primeiro em junho de 2002 em pomar de laranja de maturação precoce, cultivar Hamlin, em Itaju, região central do estado de São Paulo, para se avaliar a captura de moscas-das-frutas em armadilhas com os atrativos Milhocina ${ }^{\circledR}$ em pH 4,5, Milhocina ${ }^{\circledR} \operatorname{com}$ bórax em pH 4,5, 6,5 e 8,5, aos 2, 4, 6 e 8 dias após a instalação no pomar. O segundo experimento foi desenvolvido de junho a agosto de 2002 (inverno seco) com Iaranja Hamlin em Itaju, e o terceiro experimento foi realizado de janeiro a março de 2003 (verão chuvoso) com laranja de maturação tardia, cultivar Natal, em Porto Feliz, região sul do estado, ambos para se avaliar as densidades de uma, duas, quatro e oito armadilhas por hectare e a relação entre a captura de moscas-das-frutas nas armadilhas e 
frutos danificados. Em Itaju, as maiores capturas de Ceratitis capitata (Wiedemann, 1824) ocorreram nas armadilhas com 0 atrativo protéico Milhocina ${ }^{\circledR}$ e bórax em pH 8,5, aos 2, 4 e 6 dias. A espécie predominante, com quase 99\% das moscas-das-frutas capturadas, foi C. capitata, sendo a proporção de fêmeas capturadas de $80 \%$ em pomar com frutos e $46 \%$ em pomar sem frutos. As capturas de fêmeas, machos, e total (fêmeas e machos) de C. capitata por armadilha, nas densidades de uma, duas, quatro e oito armadilhas por hectare, foram semelhantes, indicando que $C$. capitata pode ser monitorada com uma armadilha por hectare em áreas de altas populações de moscas. Houve correlações entre a captura de fêmeas, e fêmeas e machos de C. capitata, e o número de frutos de laranja precoce 'Hamlin' danificados, sete e quatorze dias após a coleta, nas densidades de uma e duas armadilhas por hectare. Foram obtidas equações que relacionam a captura com o dano. Assim, para um dano de um fruto por árvore, o nível de controle poderia ser de 8 a 16 indivíduos de $C$. capitata por armadilha por dia. As perdas médias estimadas devido ao ataque de $C$. capitata em laranja precoce chegaram a 2,5 toneladas de frutos por hectare, ou 7,5\% da produção. Em Porto Feliz, onde predominou Anastrepha fraterculus (Wiedemann, 1830), as capturas foram baixas e o dano foi observado mais freqüentemente não sendo correlacionado com as capturas de moscas-das-frutas nas armadilhas. 


\title{
FRUIT FLIES IN ORANGE GROVES: TRAP DENSITY FOR MONITORING, EFFECT OF ATTRACTANT PH AND ESTABLISHIMENT OF AN ACTION THRESHOLD LEVEL
}

\author{
Author: PAULO EDUARDO BRANCO PAIVA \\ Adviser: Prof. Dr. JOSÉ ROBERTO POSTALI PARRA
}

\section{SUMMARY}

This research aimed to evaluate the effect of different levels of $\mathrm{pH}$ and the exposure time of the trap in the field, baited with Milhocina ${ }^{\circledR}$ and borax (sodium borate), on capturing fruit flies, to study different densities of McPhail trap for monitoring fruit flies and to establish the relation between fruit fly catches in traps and damaged orange fruits to determine injury and action threshold levels for fruit flies in orange groves. Three field experiments were carried out: the first one conducted in June of 2002 in a 'Hamlin' orange grove in Itaju, central region of state of Sao Paulo, to evaluate the trap with Milhocina ${ }^{\circledR}$ as attractant at pH 4.5 and Milhocina ${ }^{\circledR}$ and borax at pH 4.5, 6.5 and 8.5. Counts of fruit fly numbers were done at 2, 4, 6 and 8 days after placing the trap in the orange grove. The second experiment was conducted from June to August of 2002 (during dry winter) in a 'Hamlin' orange grove in Itaju, and the third one was conducted from January to March of 2003 (during rainy summer) in a 'Natal' orange grove in Porto Feliz, in southern region of state of Sao Paulo, both to evaluate the densities of one, two, four and eight traps per hectare and to study 
the relationship between fruit fly catches in the traps and damaged fruits. In Itaju, the highest catches of Ceratitis capitata (Wiedemann, 1824) were observed in traps baited with Milhocina $₫$ and borax at pH 8.5 after 2, 4 and 6 days. The most abundant fruit fly species was $C$. capitata, comprising almost $99 \%$ of the fruit flies captured, and the proportion of female catches was $80 \%$ in groves with fruits and $46 \%$ in groves without fruits. The fruit fly catches per trap were similar at different trap densities, indicating that $C$. capitata could be monitored by using one trap per hectare in areas with high fruit fly populations. Significant linear correlations were observed between females, males and females catches and damaged fruits in the following week and one week later, at densities of one and two traps per hectare. The action threshold level estimated ranged from 8 to $16 C$. capitata per trap per day for one damaged fruit per tree. The mean estimated damage caused by $C$. capitata in 'Hamlin' orange was $2,500 \mathrm{~kg}$ of fruits per hectare which corresponds to $7.5 \%$ of the total yield. Anastrepha fraterculus (Wiedemann, 1830) was the predominant species in Porto Feliz. In this experiment, the fruit fly catches were low, the intensity of damaged fruits was higher and there was no correlation with fruit fly catches in the traps. 


\section{INTRODUÇÃO}

Moscas-das-frutas são importantes pragas da cultura de citros no Brasil. No estado de São Paulo, onde se concentra $80 \%$ da produção brasileira de citros, são perdidas anualmente mais de 60 mil toneladas de frutos pelo ataque deste grupo de insetos (Nascimento et al., 1993).

Além das perdas causadas pela queda e apodrecimento dos frutos atacados, há restrições comerciais e fitossanitárias à exportação de frutas frescas para países onde esses insetos não ocorrem. A aplicação de inseticidas em frutos próximos da maturação e colheita, estágios mais suscetíveis às moscas-das-frutas, pode deixar resíduos no produto final, na fruta ou no suco de laranja.

Em frutos cítricos ocorrem as espécies de moscas-das-frutas Ceratitis capitata (Wiedemann, 1824), Anastrepha fraterculus (Wiedemann, 1830), Anastrepha obliqua (Macquart, 1835) (Diptera:Tephritidae) e moscas que pertencem à família Lonchaeidae (Malavasi \& Morgante, 1980; Souza Filho et al., 2000).

Apesar de citros não ser um bom hospedeiro para moscas-das-frutas, a presença de hospedeiros primários nos arredores de pomares de citros, como o café para C. capitata e de plantas da família Myrtaceae para A. fraterculus, favorece aumentos populacionais destes insetos, resultando em maior dano nos citros (Nascimento \& Morgante, 1990). Por isso, o monitoramento dos adultos, com armadilhas, é fundamental para o manejo integrado deste grupo de pragas.

As moscas-das-frutas podem ser monitoradas com armadilhas contendo atrativos alimentares como hidrolizados protéicos, sucos de frutas, melaços, 
vinagres e outros (Aluja, 1994). A mosca C. capitata pode ainda ser monitorada com o paraferomônio trimedlure, que captura machos desta espécie (White \& Elson-Harris, 1992). A vantagem do uso de atrativos alimentares é que eles permitem monitorar simultaneamente as duas principais espécies em citros, $C$. capitata e $A$. fraterculus, além dos lonqueídeos e outros tefritídeos.

No entanto, não se conhece a melhor densidade de armadilhas para o monitoramento destes insetos, e nem mesmo se existe uma relação entre insetos capturados nas armadilhas e o dano causado. Se houver relação entre insetos capturados, em uma determinada densidade e o dano, poderão ser determinados níveis de dano econômico e de controle para esta praga.

Assim, na presente pesquisa, foi proposto (1) avaliar o efeito do $\mathrm{pH}$ e do tempo de permanência do atrativo alimentar na captura de moscas-das-frutas, (2) avaliar diferentes densidades de armadilhas para monitoramento destes insetos em cultura de laranja, Citrus sinensis e (3) conhecer a relação numérica entre insetos capturados e frutos danificados, com vistas à determinação dos níveis de dano e de controle para moscas-das-frutas na cultura de citros. 


\section{REVISÃO DE LITERATURA}

As fêmeas das moscas-das-frutas colocam ovos no interior dos frutos. Destes ovos, eclodem as larvas que se alimentam da polpa do fruto, passando por três ínstares larvais. Após o desenvolvimento larval, as larvas saem dos frutos e caem no solo onde pupam. Com a emergência dos adultos, completase o ciclo biológico, com uma média de 30 dias, em condições climáticas ótimas para o período ovo-adulto. (Malavasi et al., 1994; Calkins \& Malavasi, 1995).

A flutuação populacional de adultos de moscas-das-frutas varia em função de dois fatores principais: a disponibilidade de hospedeiro suscetível e fatores climáticos. Em pomares de uma só frutífera, a população atinge seu pico populacional logo depois da maturação dos frutos, e cai quando não há hospedeiro disponível (Aluja, 1994; Nascimento \& Carvalho, 2000). A seqüência de frutificação de um ou mais hospedeiros simultaneamente, mantém populações de moscas-das-frutas suficientemente altas para causarem danos em várias frutíferas (Calkins \& Malavasi, 1995). Exemplo disso ocorre no estado de São Paulo, onde grandes populações de moscas-das-frutas, especialmente de Ceratitis capitata (Wiedemann, 1824), são produzidas em frutos maduros de café, entre o período de março a setembro, e estes insetos migram para outros hospedeiros, como citros, podendo causar sérios danos a esta cultura (Nascimento \& Morgante, 1990; Souza Filho et al., 2000). 


\subsection{Espécies de moscas-das-frutas em citros}

Em estudo dos hospedeiros das moscas-das-frutas de ocorrência no Brasil, Malavasi \& Morgante (1980) verificaram que $13,7 \%$ das moscas que emergiram de frutos de Citrus spp. eram insetos do gênero Anastrepha, 43,1\% eram insetos da espécie $C$. capitata, e 43,2\% eram lonqueídeos do gênero Neosilba. No entanto, os autores não citaram as espécies de Citrus dos frutos hospedeiros. Enfatizaram que Citrus foi o hospedeiro em que Neosilba ocorreu em maior freqüência, demonstrando sua importância como praga desta frutífera.

Em trabalho complementar, Malavasi et al. (1980) encontraram duas espécies de tefritídeos em frutos de laranja doce, Citrus sinensis, ou seja, C. capitata e Anastrepha fraterculus (Wiedemann, 1830) e lonqueídeos do gênero Neosilba. Em outras espécies do gênero Citrus, como C. aurantium, C. deliciosa, C. grandis, C. madurensis e $C$. reticulata, também ocorreram as três espécies de moscas, C. capitata, Anastrepha sp. e Neosilba spp.. A ocorrência destes insetos foi verificada em todo o estado de São Paulo, predominando em áreas de produção comercial de frutas, e em campos cerrados com frutos silvestres.

Apesar de citadas como insetos que emergiram de frutos cítricos, moscas da família Lonchaeidae têm importância controversa como pragas agrícolas. Estes insetos foram estudados por Souza et al. (1983), que observaram que eles somente realizaram posturas em frutos de café, pêssego e maçã, já ovipositados por um tefritídeo, C. capitata ou $A$. fraterculus. Citando Souza et al. (1983), Malavasi et al. (1994) consideraram que o mesmo poderia estar acontecendo em citros.

Fernandes (1987) verificou que 95,65\% dos tefritídeos coletados em armadilhas, em pomar de laranja (C. sinensis) cultivar 'Pêra' em São Paulo, pertenciam à espécie $C$. capitata, e apenas $4,35 \%$ ao gênero Anastrepha, com 
predominância de $A$. fraterculus. As maiores ocorrências de C. capitata foram constatadas em final de julho e início de agosto.

Souza Filho et al. (2000) em revisão sobre moscas-das-frutas em São Paulo, não mencionaram a ocorrência de lonqueídeos como insetos de importância econômica na fruticultura deste estado. Citaram C. capitata e $A$. fraterculus como as principais espécies de moscas-das-frutas de São Paulo, a primeira ocorrendo especialmente em plantas introduzidas, e a segunda, considerada a mais importante, pela ampla distribuição e importância das plantas que atacam.

Em trabalho de levantamento de mosca-das-frutas em dois pomares de C. sinensis no Mato Grosso do Sul, Uchôa-Fernandes et al. (2003) verificaram que a mosca predominante, em armadilhas McPhail contendo proteína de milho, foi Neosilba, sendo também a única mosca que emergiu dos frutos de laranja atacados. Os autores sugeriram que este inseto pode ter importância econômica como praga de citros naquele estado.

\subsection{Atrativos para monitoramento}

Moscas-das-frutas podem ser atraídas e capturadas em armadilhas com atrativos alimentares, como hidrolizados de proteínas, substâncias ricas em açúcares (melaços), vinagres de vinhos e sucos de frutas (Aluja, 1994) ou substâncias especiais, às vezes chamadas paraferomônios, como o trimedlure que atrai machos do gênero Ceratitis (White \& Elson-Harris, 1992; Lima, 2001).

Lopez \& Hernandez Becerril (1967) testaram setenta e seis aditivos em hidrolizados protéicos de milho, em diferentes dosagens, e concluíram ser o borato de sódio (bórax), o mais adequado para inibir a decomposição do atrativo (PIB-7). Este conservante evitou a decomposição e a descoloração das moscas, e reduziu a captura de outros insetos, especialmente dípteros. Nas concentrações empregadas, de 1, 2 e 3\% de bórax na solução atrativa, houve aumento e estabilização do pH da solução por 7 dias. 
Pode haver efeito do clima na eficiência das armadilhas de moscas-dasfrutas. A captura de C. capitata em armadilhas com soluções atrativas líquidas foi maior em regiões secas do que em regiões úmidas, em cerca de 18 vezes (Cunninghan et al., 1978). A causa da maior eficiência da solução atrativa em condições secas, apontada pelos autores, foi a combinação da falta de fontes de água e de alimento para os adultos.

Bateman \& Morton (1981) evidenciaram a importância da produção de amônia, em atrativos protéicos, como a substância volátil atrativa à espécie Bractrocera tryoni (Froggatt, 1897). Estes autores verificaram um aumento da atratividade devido à maior produção de amônia, em produtos com pH mais elevado. As maiores capturas foram obtidas no atrativo com pH 8,5, comparado aos demais com pH 2,5, 4,5 e 6,5. Eles sugeriram que a atração de um hidrolizado pode aumentar, com a simples elevação do pH, já que hidrolizados protéicos comerciais são ácidos, devido à hidrólise ácida ou enzimática a que são submetidos no processo industrial.

Morton \& Bateman (1981) mostraram que substâncias nitrogenadas como aminoácidos e peptídeos, presentes em hidrolizados protéicos, funcionaram como estimulantes de alimentação para a mosca $B$. tryoni, e que seriam um dos fatores responsáveis pela captura dos insetos em armadilhas do tipo McPhail, aliados ao efeito da atração olfativa da amônia.

As fêmeas de C. capitata foram mais atraídas e capturadas do que os machos em armadilhas, com proteína hidrolizada de milho, em lavouras de café em São Paulo. Estes insetos predominaram no período de maio a setembro em Campinas e de março a agosto em Pindorama, período de maturação dos frutos de café (Parra et al., 1982).

$\mathrm{Na}$ Costa Rica, houve aumento do período de ação de hidrolizados protéicos (proteína de soja), quando misturados com tetraborato de sódio, pela maior conservação do atrativo. O estudo foi feito em pomar de goiaba, com predominância de Anastrepha spp. (Jiron \& Soto-Manitiu, 1989). 
A produção de amônia tem sido observada entre os hidrolizados protéicos estudados até agora, dos quais o hidrolizado de milho é o mais eficiente e de menor custo (Roessler, 1989).

O tempo de permanência no campo com a conseqüente decomposição dos atrativos, fermento de pão, vinagre de uva e suco de pêssego, segundo Salles (1999), aumentou o efeito de atração destes compostos, sendo que as maiores capturas de $A$. fraterculus em pomares de pêssego no Rio Grande do Sul, ocorreram aos 8 dias após a instalação das armadilhas com fermento, e aos 10 dias, nas armadilhas com vinagre e com suco de pêssego.

A utilização de armadilhas à base unicamente de feromônio sexual para monitoramento e controle de diferentes espécies de moscas-das-frutas no campo, ainda não pode ser empregada, pois nos tefritídeos o sistema de feromônios e semioquímicos envolve outros aspectos olfativos, como voláteis de plantas e odores associados a seus alimentos (Lima, 2001).

\subsection{Densidade de armadilhas para monitoramento}

Em experimento de liberação e recaptura de Anastrepha suspensa (Loew, 1862) irradiadas, em pomar de citros nos EUA, Calkins et al. (1984) determinaram a probabilidade de detecção de pequenas e médias populações deste inseto. Altas populações, com 999 insetos liberados em 0,4 ha, foram facilmente detectadas com densidades de 1 e 2 armadilhas McPhail. No entanto, para detectar uma população baixa, de 9 moscas por 0,4 ha, os mesmos autores estimaram que seriam necessárias 33 armadilhas na referida área. As grandes densidades de armadilhas estimadas pelos autores, para monitoramento de baixa população de moscas-das-frutas, são de alto custo e não aplicáveis em programas de monitoramento.

Orth et al. (1986) recomendaram diferentes densidades de armadilhas para monitoramento de $A$. fraterculus em pomares de macieira em Santa Catarina, dependendo da área do pomar, sem, no entanto justificarem o 
emprego de tais densidades. Para pomares menores que 2 ha, sugerem 0 emprego de 4 armadilhas. Em áreas de 2 a 5 ha, o número de armadilhas recomendado é de 2 por ha. Se o pomar tiver entre 5 e 20 ha, utilizar 10 armadilhas e mais 1 armadilha a cada 2 hectares. Em pomares com mais que 20 ha, devem ser instalados 5 ou mais pontos de monitoramento, com 4 armadilhas por ponto.

Em pomar com várias frutíferas hospedeiras, como citros, serigüela, goiaba, pêssego, manga, abacate, café e outras, das 46.740 Anastrepha liberadas, apenas 6,7\% foram recapturadas, segundo Bressan \& Costa Teles (1991), em armadilhas adesivas coloridas e armadilhas com atrativo alimentar. Esta taxa de recaptura foi atribuída à pequena dispersão de vôo dos insetos em ambiente abundante em frutos hospedeiros, e não pela ineficiência das armadilhas utilizadas.

Aluja (1994) citou que a armadilha do tipo McPhail é ineficiente na captura de moscas do gênero Anastrepha, apesar de ser amplamente utilizada. Em pomar nativo de mangas no México ele verificou que apenas $31,1 \%$ das moscas, Anastrepha ludens (Loew, 1873), Anastrepha obliqua (Macquart, 1835) e Anastrepha serpentina (Wiedemann, 1830), que pousaram no exterior das armadilhas foram capturadas. Apesar de ser considerado caro, de difícil manuseio, de capturar preferencialmente fêmeas e de ser ineficiente, a utilização de armadilhas do tipo McPhail com hidrolizados protéicos se constitui em um dos métodos de monitoramento mais empregados para moscas-dasfrutas em todo mundo.

Kovaleski et al. (2000) propuseram a instalação de quatro armadilhas por hectare, contendo suco de pêssego diluído a $10 \%$, para monitoramento da espécie $A$. fraterculus em pomares de maçã no Rio Grande do Sul. Reiteraram a importância da padronização de armadilhas e atrativos para que o nível de controle seja bem definido. 


\subsection{Relação entre captura de moscas-das-frutas e dano}

Em pesquisa com C. capitata em laranja doce $C$. sinensis, na Nigéria, Agunloye (1987) considerou que não houve, aparentemente, uma relação direta entre queda de frutos de diferentes variedades de laranja e o número de $C$. capitata capturado em armadilhas, contendo a mistura de mel, açúcar e inseticida. $\mathrm{O}$ autor comparou a captura total dos insetos com o número de frutos atacados, em uma única data.

Já Fernandes (1987) em trabalho realizado no Brasil (Pirassununga, São Paulo), com laranja doce, cultivar Pêra, concluiu que existe uma correlação direta entre a captura de moscas-das-frutas, em pomar com predominância de C. capitata, e queda de frutos infestados. Este autor verificou que a maior queda de frutos ocorreu após 35 e 49 dias da captura de C. capitata, e após 49 e 63 dias da captura de $A$. fraterculus.

Por outro lado, não foi encontrada correlação, por Uchôa-Fernandes et al. (2003), entre adultos de lonqueídeos (Neosilba) capturados em armadilhas com larvas e adultos destes mesmos insetos obtidos de frutos infestados em pomares de laranja, no Mato Grosso do Sul.

Apesar de não haver estudos específicos em citros, no Brasil e no mundo, Malavasi et al. (1994) recomendaram como nível de controle, sete moscas do gênero Anastrepha por armadilha McPhail (com atrativo alimentar) por semana, ou quatorze machos de C. capitata por armadilha delta (com trimedlure), por semana. Nascimento et al. (2000) confirmaram esses valores, sugerindo que sejam adotados em diferentes regiões e países, como uma padronização internacional. 


\section{MATERIAL E MÉTODOS}

O atrativo utilizado foi a Milhocina ${ }^{\circledR}$ (Corn Products Brasil), que é uma água concentrada resultante da maceração de milho, com teor de proteína de 25\%, não devendo ser considerada proteína hidrolizada ou hidrolizado protéico (Fernandes, 1999). A este produto foi adicionado 5\% (peso / volume) de tetraborato de sódio decahidratado (bórax). $\mathrm{O}$ pH do atrativo foi ajustado com solução de hidróxido de sódio até 8,5 , constituindo-se no concentrado atrativo padrão. Para verificação de $\mathrm{pH}$, empregou-se um medidor de $\mathrm{pH}$ portátil marca Corning.

As armadilhas usadas foram as do tipo McPhail, modelo Mata-Sete ${ }^{\circledR}$ (Isca Tec), com as seguintes especificações: base amarela de polipropileno com $17 \mathrm{~cm}$ de diâmetro, e parte superior transparente de policarbonato, com diâmetro de $17 \mathrm{~cm}$ e 13,5 cm de altura.

A diluição do concentrado atrativo foi de $5 \%$ (volume / volume), sendo que em cada armadilha foram colocados $240-250 \mathrm{ml}$ de solução atrativa. As armadilhas foram instaladas nas árvores (laranjeiras) a aproximadamente um metro e meio de altura do solo, em local sombreado (Figura 1 A e 1 B). Foram retirados os ramos abaixo da armadilha que pudessem dificultar ou impedir a entrada dos insetos. Nos experimentos empregou-se o atrativo padrão, com Milhocina ${ }^{\circledR}$ mais bórax e correção de $\mathrm{pH}$ para 8,5 pois as maiores capturas ocorrem em atrativos com este $\mathrm{pH}$ (Bateman \& Morton, 1981).

Para separação dos insetos, o conteúdo líquido das armadilhas foi colocado em peneira, sendo que os insetos ficaram retidos. A peneira, então, era disposta em uma bacia com água, o que permitia que os insetos flutuassem 
e fossem assim identificados (Figura 1 C e 1 D). As moscas-das-frutas foram contadas e separadas por sexo. Os machos de $C$. capitata foram identificados pela presença de dois apêndices na cabeça, em forma de espátula (Gallo et al., 2002), e as fêmeas do gênero Anastrepha e da família Lonchaeidae pelo ovipositor.

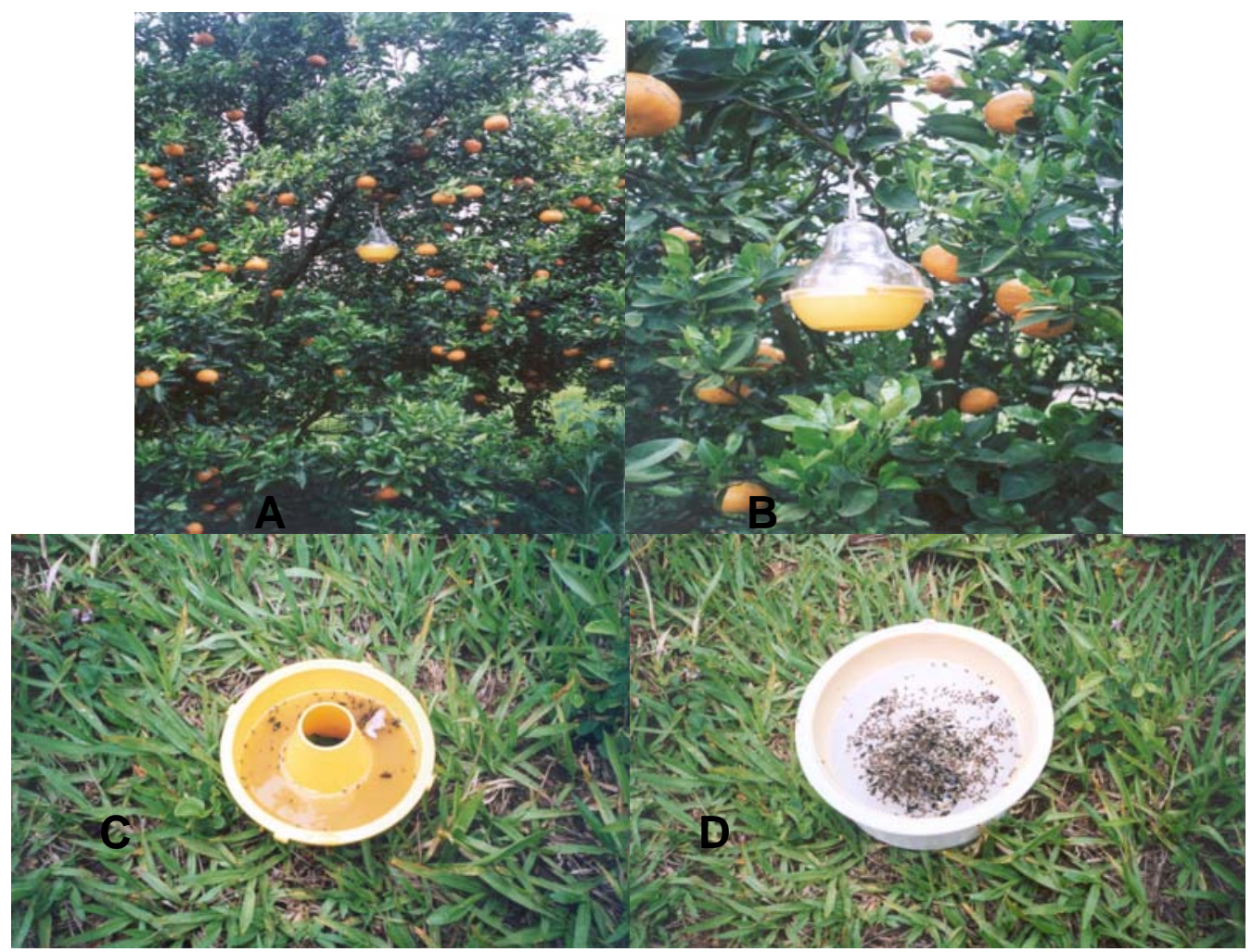

Figura 1 - Características da avaliação de moscas-das-frutas nos experimentos. (A) localização da armadilha na árvore a 1,5 m de altura do solo; (B) armadilha McPhail modelo Mata-Sete $\AA$; $(C)$ base da armadilha com solução atrativa e os insetos capturados; (D) separação dos insetos com peneira

As moscas do gênero Anastrepha e da família Lonchaeidae foram colocadas em frascos com álcool 70\%, e ao final dos experimentos, enviadas aos taxonomistas, Eng. Agr. MSc. Miguel Francisco de Souza Filho (Instituto Biológico de Campinas, SP) e ao Biólogo Pedro Carlos Strikis (Universidade Estadual de Campinas), respectivamente, para identificação específica. 


\subsection{Efeito do pH e do tempo de permanência do atrativo na captura de espécies de moscas-das-frutas (Experimento 1)}

O experimento foi realizado em pomar de laranja doce, Citrus sinensis, cultivar Hamlin, de maturação precoce, em Itaju (latitude $21^{\circ} 54^{\prime}$ sul; longitude $48^{\circ} 48^{\prime}$ oeste), região central do estado de São Paulo, em junho de 2002. O pomar de 10 hectares, era formado por árvores de 5 anos de idade, que estavam sem frutos, pela colheita recente. As árvores, espaçadas de 7,5 por 3 metros, tinham de 2 a 2,5 metros de altura.

Adotou-se o delineamento inteiramente casualizado, com quatro tratamentos e seis repetições. Os tratamentos foram: (1) Milhocina ${ }^{\circledR}$ em pH 4,5, (2) Milhocina ${ }^{\circledR}$ + bórax em pH 4,5, (3) Milhocina ${ }^{\circledR}+$ bórax em pH 6,5 e (4) Milhocina ${ }^{\circledR}+$ bórax em pH 8,5.

As armadilhas modelo McPhail com os atrativos (tratamentos) foram distribuídas ao caso, distantes 30 metros uma da outra. O atrativo concentrado foi diluído a $5 \%$ e, a seguir, distribuído nas armadilhas. As avaliações foram feitas com 2, 4, 6 e 8 dias após a instalação do experimento, avaliando-se o efeito do $\mathrm{pH}$ e o tempo de permanência do atrativo no campo. Após cada avaliação, as armadilhas eram novamente casualizadas. O conteúdo das armadilhas com os insetos foi peneirado, separando-se as moscas-das-frutas, que foram contadas e identificadas. Após a contagem dos insetos, verificou-se o pH da solução atrativa e o líquido foi devolvido à armadilha.

Foi anotado o total de machos e fêmeas de moscas-das-frutas em cada avaliação e realizada a análise de variância (teste $F$ ), sendo as médias comparadas pelo teste de Tukey ao nível de $5 \%$ de probabilidade, com auxílio do programa Sanest. Foi correlacionado o $\mathrm{pH}$ inicial do atrativo e a captura das moscas-das-frutas, com o software Table-Curve. 


\subsection{Determinação da densidade de armadilhas para monitoramento e relação entre moscas-das-frutas capturadas e frutos danificados, em laranja de maturação precoce (Experimento 2)}

O experimento foi realizado em pomar de laranja doce, Citrus sinensis, cultivar Hamlin, no município de Itaju / SP, de junho a agosto de 2002. A área experimental foi composta de dois talhões vizinhos de 14 hectares cada, dentro de uma área contínua de citros de 700 hectares. As árvores tinham 5 anos de idade e altura de 2 a 2,5 metros. Os frutos apresentavam coloração amarela e tinham aproximadamente nove meses de idade (provenientes do florescimento de outubro de 2001), e estavam maduros no início do experimento, em ponto de colheita para a cultivar. O espaçamento entre as árvores era de 7,5 por 3 metros, com 444 plantas por hectare.

Os tratamentos foram quatro densidades de armadilhas: uma, duas, quatro e oito armadilhas por hectare, com 5 repetições (Figura 2). Adotou-se o delineamento inteiramente casualizado, com parcelas quadradas de 110 metros de lado e área útil de 100 por 100 metros (1 hectare). As armadilhas foram distribuídas de forma eqüidistante na área útil, do centro da parcela para o exterior, com 25 metros de distância entre elas. 


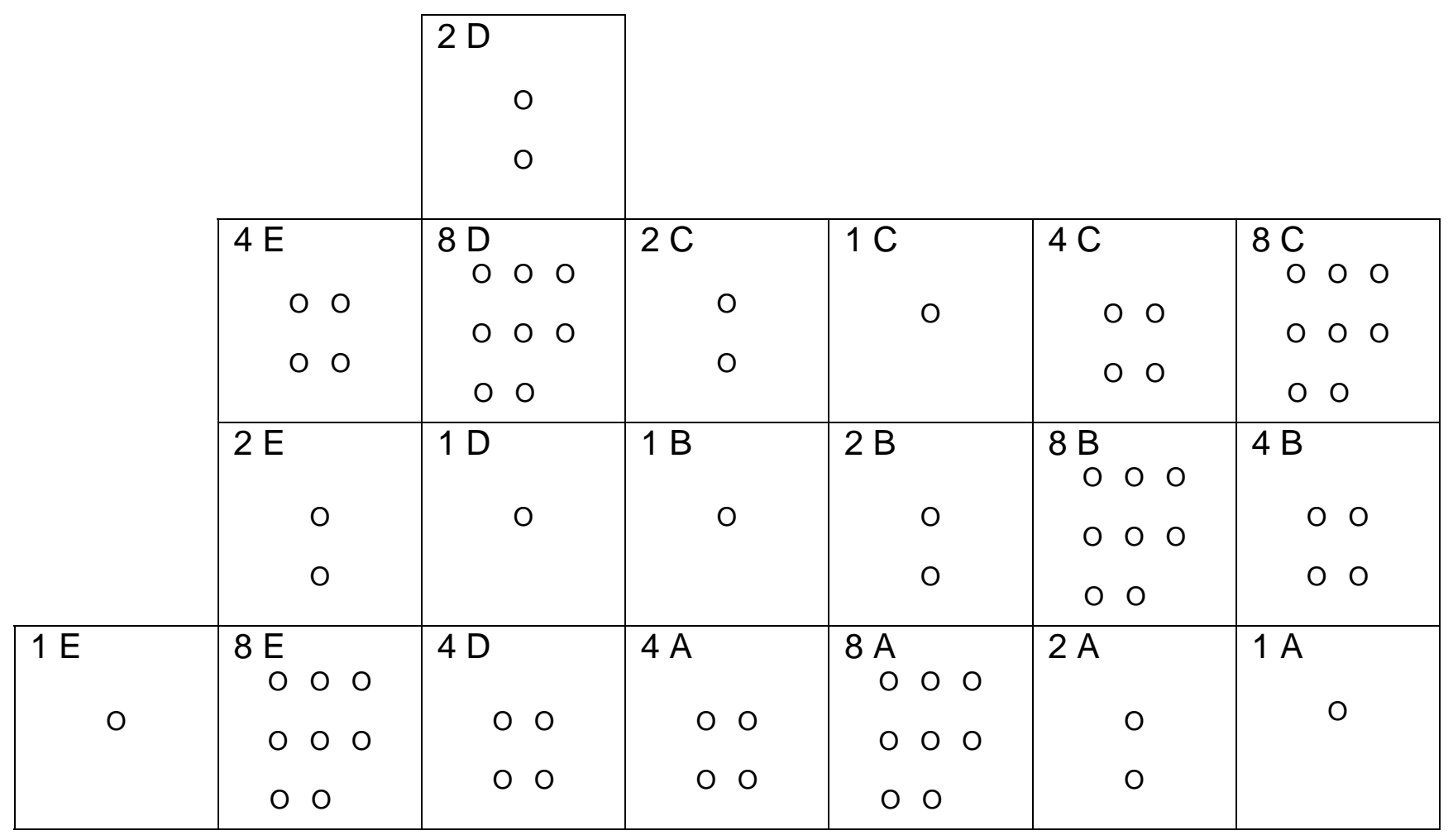

Figura 2 - Croqui da área experimental de laranja cultivar Hamlin, com a distribuição das parcelas para monitoramento e para estudo da relação entre moscas-das-frutas capturadas e frutos danificados. Itaju ISP, 2002. Os círculos representam as armadilhas, o número, o tratamento e a letra a repetição

As armadilhas foram instaladas no período da manhã e a avaliação das moscas-das-frutas ocorreu na manhã seguinte, 24 horas após, pois na primeira avaliação com exposição das armadilhas por 7 dias, houve decomposição dos insetos, pelo excesso de indivíduos coletados. O conteúdo das armadilhas foi peneirado e os insetos foram identificados, sendo as moscas-das-frutas contadas e separadas por sexo. As armadilhas foram mantidas nas plantas, sem solução atrativa, até a próxima avaliação, na semana seguinte. Com o número de moscas-das-frutas capturado nas armadilhas, nas densidades duas, quatro e oito armadilhas por hectare, obteve-se a média aritmética da parcela. 
Para avaliação do dano, feita semanalmente, foram marcadas nove árvores em cada parcela, nas quais contou-se o número de frutos atacados por moscas-das-frutas na árvore e caídos no solo. Para início do experimento, retiraram-se todos os frutos danificados das plantas marcadas. Os frutos contados foram retirados da área, para que não fossem contados novamente na avaliação seguinte.

Havia um pluviômetro a 100 metros da área experimental, onde as precipitações pluviométricas foram registradas.

O número de moscas-das-frutas capturado e de frutos danificados foi anotado e com eles foram realizadas a análise de variância (Teste F) e a comparação de médias pelo teste de Tukey ao nível de 5\% de probabilidade, com auxílio do software Sanest. Foi correlacionada a captura das moscas-dasfrutas e o dano ocorrido na semana anterior à captura e nas duas semanas posteriores (Tabela 1), através do software Table-Curve.

Tabela 1. Correlação testada entre a data de captura de moscas-das-frutas e o período do dano causado por esses insetos em frutos de laranja de maturação precoce, na semana anterior e nas semanas posteriores, após 7 e 14 dias da instalação das armadilhas. Itaju /SP, 2002

\begin{tabular}{|c|c|c|c|}
\hline \multirow{2}{*}{$\begin{array}{l}\text { Período da captura } \\
\text { (dia da avaliação) }\end{array}$} & \multicolumn{3}{|c|}{ Período do dano (dia da avaliação) } \\
\hline & Semana anterior & $\begin{array}{c}\text { Semana posterior } \\
\text { (1-7 dias) }\end{array}$ & $\begin{array}{c}\text { Semana posterior } \\
\text { (8-14 dias) }\end{array}$ \\
\hline $5-6 / j u l$ & 29/jun-5/jul & 6/jul-12/jul & 13/jul-19/jul \\
\hline 12-13/jul & 6/jul-12/jul & 13/jul-19/jul & 20/jul-26/jul \\
\hline 19-20/jul & 13/jul-19/jul & 20/jul-26/jul & 27/jul-2/ago \\
\hline 26-27/jul & 20/jul-26/jul & 27/jul-2/ago & 3/ago-9/ago \\
\hline 3-4/ago & 27/jul-2/ago & 3/ago-9/ago & - \\
\hline 9-10/ago & 3/ago-9/ago & - & - \\
\hline
\end{tabular}




\subsection{Determinação da densidade de armadilhas para monitoramento e relação entre moscas-das-frutas capturadas e frutos danificados, em laranja de maturação tardia (Experimento 3)}

O experimento foi realizado em pomar de laranja doce, Citrus sinensis, cultivar Natal, no município de Porto Feliz / SP (latitude $23^{\circ} 18^{\prime}$ sul; longitude $47^{\circ} 24^{\prime}$ oeste), região sul do estado de São Paulo, no período de janeiro a março de 2003. A área experimental tinha cerca de 24 hectares, dentro de uma área de citros de 200 hectares. As árvores estavam com 23 anos de idade e altura entre 5 e 5,5 metros, em espaçamento de 8 por 5 metros, resultando em uma densidade de 250 plantas por hectare. As plantas apresentavam dois tipos de frutos, completamente desenvolvidos e maduros com 16 meses de idade (provenientes do florescimento de setembro de 2001), em ponto de colheita, e frutos em desenvolvimento e verdes, com 4 meses (provenientes do florescimento de setembro de 2002).

Adotou-se metodologia semelhante à descrita no item 3.2; no entanto, as armadilhas permaneceram com a solução atrativa durante sete dias, pois na primeira avaliação houve pequena captura de moscas-das-frutas. $E$ a avaliação de dano foi feita em seis árvores marcadas por parcela. Os tratamentos foram distribuídos ao acaso na área experimental (Figura 3). Com os dados obtidos, de moscas-das-frutas capturadas e frutos danificados, foram obtidas as médias. Os dados foram submetidos à análise de variância e feita a comparação de médias pelo teste de Tukey ao nível de $5 \%$ de probabilidade.

As precipitações pluviométricas foram registradas diariamente em pluviômetro, localizado a 50 metros do experimento. 


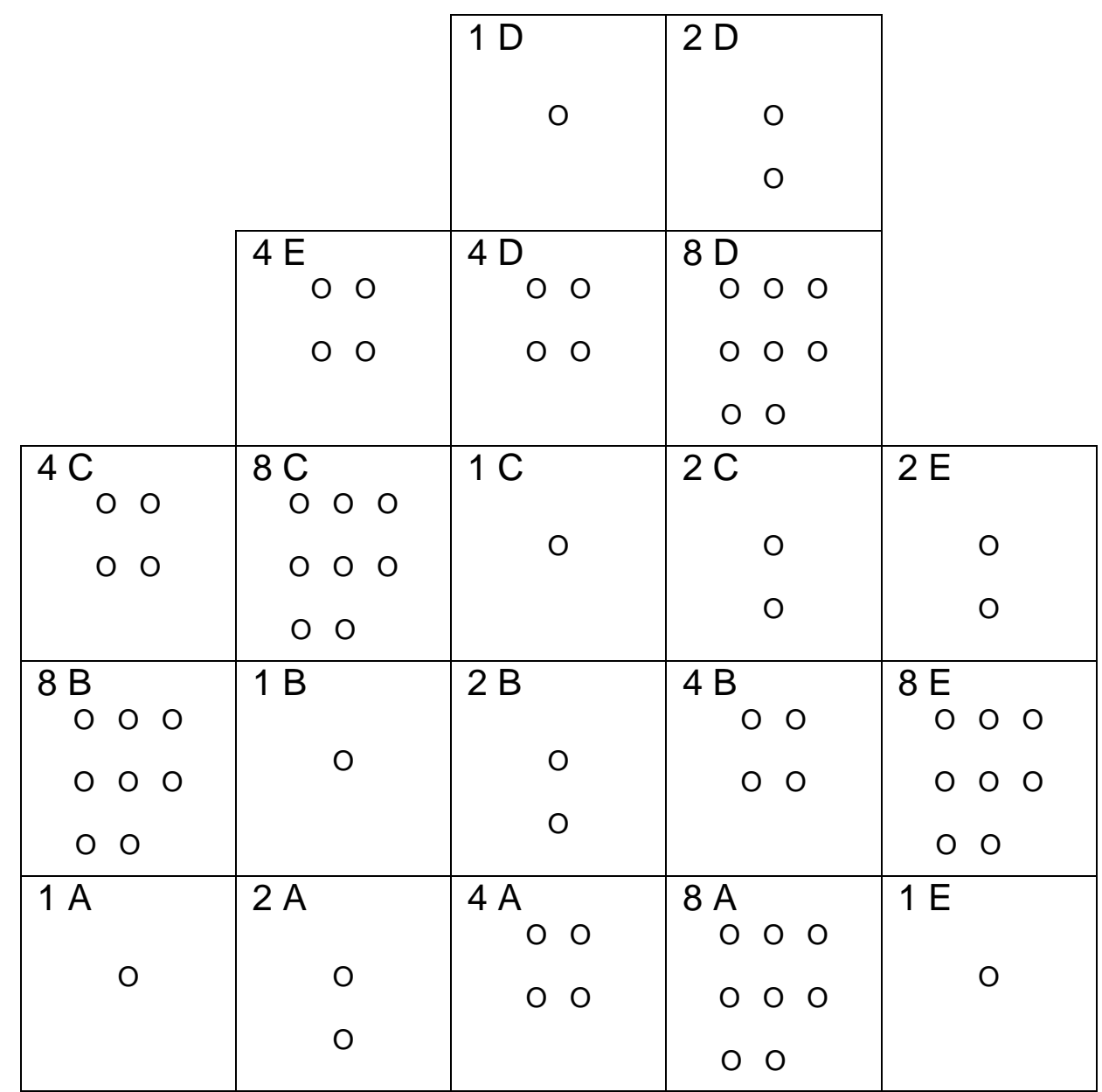

Figura 3 - Croqui da área experimental de laranja cultivar Natal, com a distribuição das parcelas para monitoramento e relação entre moscas-das-frutas capturadas e frutos danificados. Porto Feliz ISP, 2003. Os círculos representam as armadilhas, o número, o tratamento e a letra a repetição 


\section{RESULTADOS E DISCUSSÃO}

\subsection{Efeito do pH e do tempo de permanência do atrativo no campo na}

captura de Ceratitis capitata (Wiedemann, 1824)

$\mathrm{O}$ pH inicial da solução atrativa e o tempo de permanência no campo influenciaram a captura da espécie C. capitata (Figura 4, Tabela 2). Houve correlação entre pH inicial e captura (Figura 5), ou seja, quanto maior o pH do atrativo utilizado neste experimento, maior a captura. As maiores capturas deste inseto foram verificadas nas armadilhas com a solução atrativa Milhocina ${ }^{\circledR}$ com bórax em pH inicial 8,5 aos 2, 4 e 6 dias após a instalação das armadilhas no pomar.



Figura 4 - Efeito do pH inicial e do tempo de permanência do atrativo na captura de Ceratitis capitata, em pomar de laranja cultivar Hamlin sem frutos. Itaju / SP, junho de 2002. Barras seguidas pelas mesmas letras minúsculas (atrativo) e maiúsculas (tempo) não diferem entre si, pelo teste de Tukey, ao nível de 5\% de probabilidade 
Tabela 2. Número total de indivíduos de Ceratitis capitata, de ambos os sexos e $\%$ de fêmeas, capturados em atrativos com diferentes $\mathrm{pH}$ iniciais, em pomar de laranja cultivar Hamlin sem frutos. Itaju / SP, junho de 2002

\begin{tabular}{lccccc}
\hline Atrativo & pH inicial & fêmeas & machos & total & \% de fêmeas \\
\hline Milhocina ${ }^{\circledR}$ & 4,5 & $59^{\mathrm{a}}$ & 84 & 143 & $41^{\mathrm{b}}$ \\
Milhocina ${ }^{\circledR}+$ bórax & 4,5 & 84 & 87 & 171 & 49 \\
Milhocina ${ }^{\circledR}+$ bórax & 6,5 & 258 & 309 & 567 & 46 \\
Milhocina ${ }^{\circledR}+$ bórax & 8,5 & 498 & 525 & 1023 & 49 \\
\hline
\end{tabular}

a: insetos obtidos em 24 exposições (6 armadilhas e 4 avaliações)

b: os valores não diferiram pelo teste do qui-quadrado

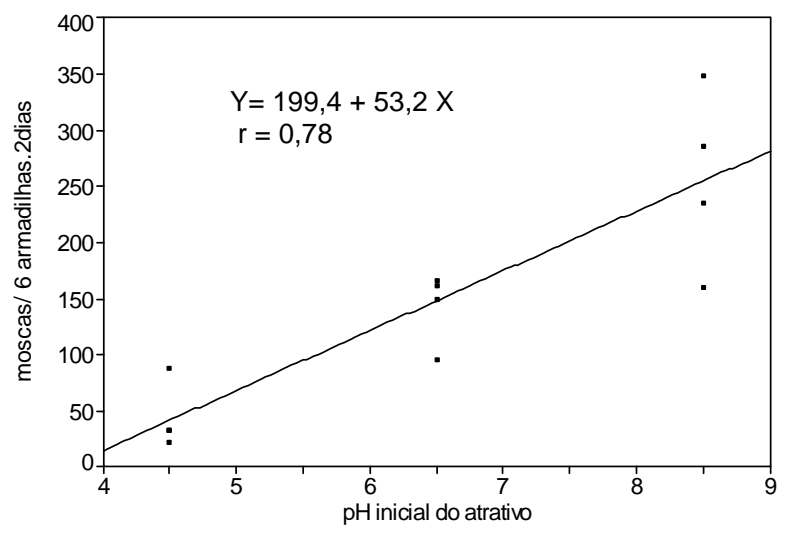

Figura 5 - Relação entre pH inicial do atrativo e a captura de Ceratitis capitata, em pomar de laranja cultivar Hamlin sem frutos. Itaju / SP, junho de 2002

Moscas do gênero Anastrepha foram poucos freqüentes, sendo que apenas quatro insetos deste gênero foram capturados durante todo 0 experimento e também não houve captura de lonqueídeos no local estudado. Para C. capitata, não houve diferença na atração de sexos entre os tratamentos (Tabela 2). 
Considerando-se o total de insetos capturados nos quatro tratamentos (atrativos), verifica-se que a solução atrativa Milhocina ${ }^{\circledR}$ e bórax com pH inicial 8,5 foi a mais eficiente para captura de C. capitata. A média de moscas capturadas, durante 2 dias, neste tratamento, nas quatro avaliações, foi de 42,6 moscas por armadilha, média seis vezes superior àquela observada com 0 atrativo Milhocina ${ }^{\circledR}$ e bórax em pH inicial 4,5 (7,1 moscas por armadilha). Bateman \& Morton (1981) constataram que as maiores capturas de Bractrocera tryoni (Froggatt, 1897), com o atrativo NBC, um hidrolizado protéico, ocorreram com $\mathrm{pH} 8,5$. Neste $\mathrm{pH}$, a captura média foi nove vezes maior do que aquela registrada no atrativo padrão, cujo pH era 4,8.

O tempo de permanência no campo da solução atrativa reduziu a captura de C. capitata nos tratamentos Milhocina ${ }^{\circledR}$ e bórax em pH inicial 4,5 e Milhocina ${ }^{\circledR}$ e bórax em pH 8,5. Na solução atrativa Milhocina ${ }^{\circledR}$ e bórax com pH 4,5 houve uma menor captura aos 6 dias comparado aos 2 dias. No atrativo com $\mathrm{pH} 8,5$, a captura aos 8 dias foi menor, significativamente, do que a realizada aos 2 dias. Resultados opostos foram obtidos por Salles (1999) com Anastrepha fraterculus (Wiedemann, 1830) em pomares de pêssego, pois este autor observou que o "envelhecimento" (tempo de permanência no campo) e a decomposição do fermento de pão (em diluição de $20 \%$ ), vinagre de uva (25\%) e suco de pêssego (10\%), utilizados como atrativos, aumentaram a captura de A. fraterculus. As espécies diferentes, bem como os atrativos, as condições climáticas, a frutífera utilizada, entre outros fatores, podem ter determinado tais diferenças.

Observou-se no decorrer do experimento, uma redução na captura de fêmeas de $C$. capitata e aumento na de machos, alterando assim a proporção sexual de captura (Figura 6). No melhor atrativo, Milhocina ${ }^{\circledR}$ e bórax em pH 8,5, a porcentagem de fêmeas capturadas era de 65 aos 2 dias, e passou a 32 aos 8 dias. Neste atrativo houve uma queda contínua da captura de fêmeas. Nos outros três atrativos, houve flutuação da proporção sexual de captura, com queda na captura de fêmeas aos 4 e 6 dias e aumento na avaliação seguinte. 




Figura 6 - Proporção de fêmeas de Ceratitis capitata capturadas em armadilhas contendo atrativos com diferentes $\mathrm{pH}$ iniciais, em pomar de laranja cultivar Hamlin sem frutos, ao longo do tempo. Itaju / SP, junho de 2002

O fato de o pomar ter tido seus frutos colhidos uma semana antes do início do experimento, possivelmente, fez com que as fêmeas deixassem esta área em busca de locais para oviposição, levando a uma predominância de machos, especialmente aos 6 dias. Fêmeas de C. capitata, com ovários maduros, tendem a permanecer nas suas plantas hospedeiras, enquanto houver frutos disponíveis para oviposição e tão logo eles se tornem escassos, há uma rápida dispersão (Yuval \& Hendrichs, 2001).

Não houve diferença significativa entre as porcentagens de captura de fêmeas nas quatro datas avaliadas. A média geral foi de $46 \%$, o que corresponde a uma pequena predominância de machos nas armadilhas.

Comparando-se os dois primeiros tratamentos, Milhocina ${ }^{\circledR}$ e Milhocina ${ }^{\circledR}$ e bórax, ambos em pH 4,5, verifica-se que a adição do conservante tetraborato de sódio hidratado (bórax) no atrativo concentrado na proporção de 5\%, não influenciou a captura de C. capitata. Em nenhuma das avaliações, houve 
diferença significativa entre as capturas desses atrativos, quando o $\mathrm{pH}$ inicial era 4,5. (Figura 4).

Com o atrativo protéico, denominado PIB-7, a 1\%, em pH de 8,5 a 9, Lopez \& Hernandez Becerril (1967) tiveram redução na captura de moscas-dasfrutas, com predominância de Anastrepha ludens (Loew, 1873), com bórax a 1, 2 e $3 \%$. Com a adição de substâncias que inibem o desenvolvimento de microorganismos pode haver redução na produção de amônia (Bateman \& Morton, 1981), e conseqüente redução na captura.

Os pH das soluções atrativas variaram ao longo do tempo (Figura 7). Nas soluções atrativas Milhocina ${ }^{\circledR}$ e bórax em pH inicial de 8,5, houve redução no $\mathrm{pH}$, para 7,0 aos 2 dias, aumentando em seguida, aos 4 dias, e se estabilizando em torno de 8,0 a partir dos 6 dias. Já a solução atrativa Milhocina ${ }^{\circledR}$ e bórax em $\mathrm{pH}$ inicial de 6,5 teve aumento de $\mathrm{pH}$ aos 4 dias, permanecendo estável em torno de 8,0 a partir desta data.



Figura 7 - Variação de pH nas soluções atrativas, a partir de diferentes pH iniciais, para captura de Ceratitis capitata, em pomar de laranja cultivar Hamlin sem frutos, ao longo do tempo. Itaju / SP, junho de 2002

As soluções atrativas, que não tiveram seu pH aumentado (sem adição de hidróxido de sódio), Milhocina ${ }^{\circledR}$ e Milhocina ${ }^{\circledR}$ e bórax com pH 4,5, 
mostraram uma pequena redução de $\mathrm{pH}$ aos 2 e 4 dias, e um aumento posterior, aos 6 e 8 dias, principalmente a solução atrativa sem bórax, que alcançou pH 6,9 aos 8 dias. No entanto, este aumento de pH não resultou em maior captura de $C$. capitata (Figura 4).

A adição de $1 \%$ de bórax no atrativo protéico (PIB-7) permitiu a estabilização do pH da solução em 8,7 até sete dias, sugerindo uma inibição da decomposição do atrativo (Lopez \& Hernandez Becerril, 1967). No presente trabalho, foi utilizado $5 \%$ de bórax no atrativo concentrado, que diluído a $5 \%$ na solução, resultou em uma concentração final de $0,25 \%$, que se mostrou incapaz de evitar a variação de $\mathrm{pH}$ nas soluções atrativas, possivelmente pela atividade microbiana existente.

\subsection{Espécies e proporção sexual de captura}

Ao longo das seis avaliações do experimento 2 (determinação da densidade de armadilhas para monitoramento e relação entre moscas-dasfrutas capturadas e frutos danificados, em laranja de maturação precoce), foram capturadas 51.532 moscas-das-frutas, das quais 50.956 foram C. capitata, 304 moscas pertenciam ao gênero Anastrepha e 272 à família Lonchaeidae (Tabela 3).

Tabela 3. Número total de moscas-das-frutas, freqüência de espécies e \% de fêmeas na captura em pomar de laranja cultivar Hamlin no experimento de determinação da densidade de armadilhas para monitoramento e relação entre moscas-das-frutas capturadas e frutos danificados. Itaju / SP, junho a agosto de 2002

\begin{tabular}{lccc}
\hline Mosca-das-frutas & Total capturado & $\%$ & \% de fêmeas \\
\hline Ceratitis capitata & 50956 & 98,88 & 80 \\
Anastrepha spp. & 304 & 0,59 & 58 \\
Neosilba spp. & 272 & 0,53 & 92 \\
\hline
\end{tabular}


Das 102 fêmeas de Anastrepha enviadas para identificação, 99 insetos eram da espécie $A$. fraterculus, e havia um inseto de cada uma das seguintes espécies: Anastrepha obliqua (Macquart,1835), Anastrepha serpentina (Wiedemann, 1830) e Anastrepha sororcula Zucchi, 1979.

Como a identificação específica de lonqueídeos é feita através do exame de machos, e poucos machos foram capturados, apenas seis espécimes puderam ser identificados. Foram encontrados três insetos da espécie Neosilba zadolicha McAlpine \& Steyskal,1982, dois da espécie Neosilba pendula (Bezzi, 1919) e um inseto de uma terceira espécie, ainda não descrita, denominada Neosilba sp. 04. Todas as fêmeas foram identificadas como pertencentes ao gênero Neosilba.

A proporção de fêmeas capturadas foi diferente entre os gêneros das moscas-das-frutas (Tabela 3). Para C. capitata e Neosilba spp. houve predominância de fêmeas nas armadilhas, e para Anastrepha spp. (com predominância de $A$. fraterculus), a proporção de fêmeas esteve próximo a $50 \%$, o que significa um número semelhante de machos e fêmeas capturados. A proporção de C. capitata fêmeas obtida em pomar com frutos foi $80 \%$, bem maior que a observada em pomar da mesma cultivar, porém sem frutos, ou seja, $46 \%$.

Valores distintos foram calculados a partir dos dados obtidos por Parra et al. (1982) com C. capitata em café. No experimento realizado em Campinas ISP, com armadilhas do tipo Valenciano contendo proteína de milho hidrolizada, a porcentagem de fêmeas capturadas desta espécie foi de 57\%, e em Pindorama 59\%. A maior atratividade e captura de fêmeas de moscas-dasfrutas em citros, com predominância de $C$. capitata, também foi observada por Fernandes (1987). 


\subsection{Efeito da densidade de armadilhas na captura de moscas-das-frutas em laranja precoce}

As maiores capturas ocorreram, como esperado, na maior densidade empregada (oito armadilhas por hectare), onde se coletaram 25.830 indivíduos pertencentes à espécie $C$. capitata, o dobro dos insetos capturados na densidade de quatro armadilhas, 12.773. Por outro lado, com a densidade de duas armadilhas por hectare foram capturados 7.830 insetos, $73 \%$ a mais que na densidade de uma armadilha (4523). O mesmo ocorreu com Anastrepha e Neosilba, que foram mais capturadas nas duas maiores densidades. Durante este experimento não ocorreram precipitações pluviométricas.

Contudo, as capturas de C. capitata por unidade não foram afetadas pelas densidades de armadilhas estudadas. Assim, independente da densidade empregada, uma, duas, quatro ou oito armadilhas por hectare, o número de insetos capturados por armadilha, não diferiu estatisticamente entre si, nas seis avaliações realizadas (Tabelas 4, 5 e 6).

Apesar de não haver diferenças estatísticas, as capturas de fêmeas, e machos e fêmeas, tenderam a ser maiores na densidade de uma armadilha por hectare, nas avaliações de 20 de julho até 10 de agosto.

Tabela 4. Número médio ( $\pm E P$ ) de fêmeas e machos de $C$. capitata capturadas por armadilha, em um dia, com diferentes densidades de armadilha. Itaju / SP, junho a agosto de 2002

\begin{tabular}{ccccccc}
\hline \multirow{2}{*}{$\begin{array}{c}\text { Armadilhas/ } \\
\text { ha }\end{array}$} & $6 / \mathrm{jul}$ & $13 / \mathrm{jul}$ & $20 / \mathrm{jul}$ & $27 / \mathrm{jul}$ & $4 / \mathrm{ago}$ & $10 / \mathrm{ago}$ \\
\cline { 2 - 6 } & $70,6 \pm 13,7 \mathrm{a}$ & $112,4 \pm 26,6 \mathrm{a}$ & $274,0 \pm 63,8 \mathrm{a}$ & $167,8 \pm 55,5 \mathrm{a}$ & $119,8 \pm 23,9 \mathrm{a}$ & $165,4 \pm 52,3 \mathrm{a}$ \\
1 & $79,6 \pm 18,3 \mathrm{a}$ & $118,0 \pm 23,9 \mathrm{a}$ & $256,0 \pm 52,7 \mathrm{a}$ & $133,5 \pm 23,9 \mathrm{a}$ & $88,7 \pm 9,9 \mathrm{a}$ & $114,6 \pm 13,6 \mathrm{a}$ \\
4 & $49,4 \pm 13,7 \mathrm{a}$ & $100,0 \pm 26,2 \mathrm{a}$ & $176,9 \pm 40,5 \mathrm{a}$ & $106,1 \pm 21,7 \mathrm{a}$ & $90,5 \pm 13,6$ a & $117,6 \pm 11,6 \mathrm{a}$ \\
8 & $46,6 \pm 15,2 \mathrm{a}$ & $99,0 \pm 17,8 \mathrm{a}$ & $208,2 \pm 33,7 \mathrm{a}$ & $100,8 \pm 15,4 \mathrm{a}$ & $88,0 \pm 9,4 \mathrm{a}$ & $105,8 \pm 10,2 \mathrm{a}$ \\
\hline
\end{tabular}


Tabela 5. Número médio ( $\pm E P$ ) de fêmeas de C. capitata capturadas por armadilha, em um dia, com diferentes densidades de armadilha. Itaju / SP, junho a agosto de 2002

\begin{tabular}{|c|c|c|c|c|c|c|}
\hline \multirow{2}{*}{$\begin{array}{c}\text { Armadilhas/ } \\
\text { ha }\end{array}$} & \multicolumn{6}{|c|}{ Avaliações } \\
\hline & $6 / j u l$ & 13/jul & 20/jul & 27/jul & 4/ago & 10/ago \\
\hline 1 & $59,0 \pm 12,5 \mathrm{a}$ & $86,0 \pm 19,7 \mathrm{a}$ & $229,4 \pm 51,1 \mathrm{a}$ & $140,0 \pm 47,9 a$ & $101,4 \pm 20,3 a$ & $115,6 \pm 35,8 a$ \\
\hline 2 & $66,3 \pm 16,6 \mathrm{a}$ & $94,3 \pm 18,7 \mathrm{a}$ & $203,0 \pm 43,2 a$ & $98,6 \pm 19,5 \mathrm{a}$ & $72,4 \pm 9,6 \mathrm{a}$ & $74,5 \pm 6,9 \mathrm{a}$ \\
\hline 4 & $41,2 \pm 12,3 \mathrm{a}$ & $77,1 \pm 19,9 \mathrm{a}$ & $139,6 \pm 31,2 a$ & $79,8 \pm 16,1 \mathrm{a}$ & $75,1 \pm 11,5 \mathrm{a}$ & $80,9 \pm 8,7 \mathrm{a}$ \\
\hline 8 & $38,8 \pm 13,2 \mathrm{a}$ & $75,6 \pm 11,9 a$ & $166,9 \pm 25,8 a$ & $76,7 \pm 10,2 \mathrm{a}$ & $71,3 \pm 7,7 \mathrm{a}$ & $75,1 \pm 7,7 \mathrm{a}$ \\
\hline
\end{tabular}

Médias da mesma coluna seguidas de letras iguais não diferem entre si, pelo teste de Tukey, ao nível de 5\% de probabilidade.

Tabela 6. Número médio $( \pm E P)$ de machos de C. capitata capturados por armadilha, em um dia, com diferentes densidades de armadilha. Itaju / SP, junho a agosto de 2002

\begin{tabular}{|c|c|c|c|c|c|c|}
\hline \multirow{2}{*}{$\begin{array}{c}\text { Armadilhas/ } \\
\text { ha }\end{array}$} & \multicolumn{6}{|c|}{ Avaliações } \\
\hline & $6 / j u l$ & 13/jul & 20/jul & 27/jul & 4/ago & 10/ago \\
\hline 1 & $11,6 \pm 2,5 \mathrm{a}$ & $26,4 \pm 7,2 \mathrm{a}$ & $44,6 \pm 13,2 \mathrm{a}$ & $27,8 \pm 7,5 \mathrm{a}$ & $18,4 \pm 4,6 \mathrm{a}$ & $49,8 \pm 16,7 \mathrm{a}$ \\
\hline 2 & $13,3 \pm 3,3 a$ & $23,7 \pm 5,3 a$ & $53,0 \pm 10,5 \mathrm{a}$ & $34,9 \pm 8,9 a$ & $16,3 \pm 2,3 \mathrm{a}$ & $40,1 \pm 7,9 \mathrm{a}$ \\
\hline 4 & $8,2 \pm 2,5 \mathrm{a}$ & $22,9 \pm 6,5 \mathrm{a}$ & $37,3 \pm 10,1 \mathrm{a}$ & $26,3 \pm 6,4$ a & $15,4 \pm 2,8 \mathrm{a}$ & $36,7 \pm 4,0 \mathrm{a}$ \\
\hline 8 & $7,8 \pm 2,6 \mathrm{a}$ & $23,4 \pm 5,9 a$ & $41,3 \pm 8,6 \mathrm{a}$ & $24,1 \pm 5,4 \mathrm{a}$ & $16,7 \pm 1,7 \mathrm{a}$ & $30 \pm 2,6 \mathrm{a}$ \\
\hline
\end{tabular}

O número total de $C$. capitata (machos e fêmeas) capturado em cada data de avaliação não diferiu entre si; no entanto, a média de insetos capturados nas seis avaliações foi maior na densidade de uma armadilha por hectare do que nas densidades de quatro e oito armadilhas, sendo que a densidade de duas armadilhas não diferiu dos demais tratamentos (Figura 8). O mesmo aconteceu com as fêmeas de $C$. capitata, que foram mais capturadas na menor densidade de armadilhas, considerando-se a média de todo o experimento. A captura média de machos não diferiu entre as densidades estudadas. 


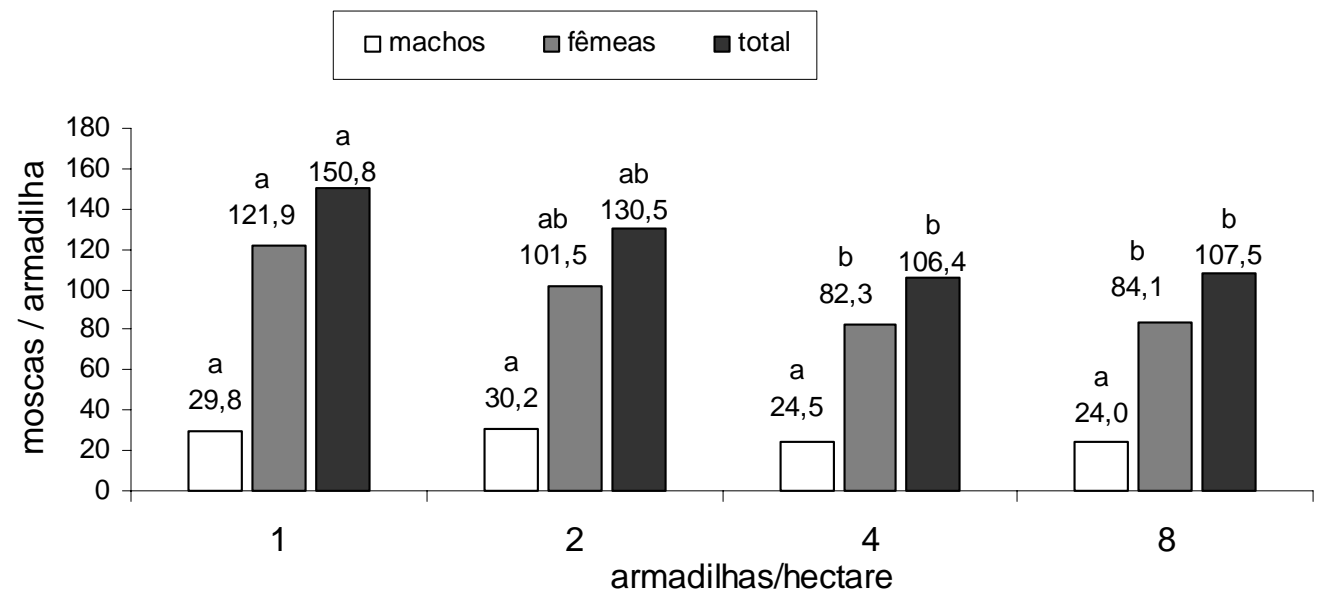

Figura 8 - Número médio (6 avaliações) de moscas Ceratitis capitata capturadas, em um dia, em pomar de laranja cultivar Hamlin, no experimento de determinação da densidade de armadilhas para monitoramento e relação entre moscas-das-frutas capturadas e frutos danificados. Itaju / SP, junho a agosto de 2002. Barras da mesma cor seguidas por letras diferentes diferem entre si pelo teste de Tukey, ao nível de 5\% de probabilidade

Assim, considerando-se apenas o número de insetos capturados, admitese que $C$. capitata poderia ser monitorada, em regiões próximas a cafezais, em áreas de citros com grandes populações deste inseto, com uma armadilha por hectare, já que nesta densidade, as capturas foram semelhantes àquelas das densidades maiores. Altas populações de moscas-das-frutas podem ser mais facilmente detectadas em armadilhas, mesmo utilizando-se baixas densidades (Calkins et al, 1984). 


\subsection{Efeito da densidade de armadilhas na captura de moscas-das-frutas em laranja tardia}

No experimento em laranja tardia, houve baixa ocorrência de moscasdas-frutas. Em apenas sete exposições, das 525 possíveis (75 armadilhas x 7 avaliações), capturaram-se moscas-das-frutas. Foram sete capturas, com um inseto em cada uma delas. Dos sete insetos obtidos, seis eram $A$. fraterculus ( 3 fêmeas) e uma $C$. capitata (fêmea). Nas parcelas do tratamento com uma armadilha por hectare, nenhuma mosca foi encontrada nas sete avaliações realizadas. Nas parcelas com duas armadilhas, obteve-se apenas uma captura. Enquanto que, nas parcelas dos tratamentos quatro e oito armadilhas por hectare, obtiveram-se três capturas em cada um dos tratamentos. Isto sugere que o aumento da densidade de armadilhas pode aumentar a chance de captura de moscas-das-frutas.

Durante o experimento, as capturas estiveram abaixo do nível sugerido por Malavasi (2000) para áreas de baixa prevalência ou de enfoque sistêmico, que é de, no máximo, três insetos por armadilha por semana. Não se pode afirmar que esta seja uma área de baixa prevalência, pois o estudo foi conduzido somente com armadilhas com atrativo alimentar e durante três meses.

Além da provável baixa população de moscas-das-frutas presente na área experimental, as precipitações pluviométricas intensas durante os meses de janeiro e fevereiro de 2003, com um total de $563 \mathrm{~mm}$ (Tabela 7), podem ter reduzido a atratividade e a captura destes insetos (Cunningham et al, 1978). As armadilhas dispostas a 1,5 metros de altura do solo em um pomar com árvores de 5 a 5,5 metros pode ter também limitado a captura de $A$. fraterculus, espécie predominante neste experimento. Salles (1995) obteve capturas desta espécie, com armadilhas localizadas de 1,5 a 10 metros de altura do solo, sendo que as maiores capturas ocorreram entre 4 e 6 metros, em vegetação com plantas hospedeiras e árvores de até 40 metros. 
Tabela 7. Precipitações pluviométricas $(\mathrm{mm})$ durante a realização do experimento de determinação da densidade de armadilhas para monitoramento e relação entre moscas-das-frutas capturadas e frutos danificados, em laranja de maturação tardia. Porto Feliz ISP, janeiro e fevereiro de 2003

\begin{tabular}{cccc}
\hline dia & $\begin{array}{c}\text { Janeiro } \\
\text { precipitação } \\
\text { pluviométrica }(\mathrm{mm})\end{array}$ & dia & $\begin{array}{c}\text { Fevereiro } \\
\text { precipitação } \\
\text { pluviométrica }(\mathrm{mm})\end{array}$ \\
\hline 5 & 63 & 13 & 30 \\
12 & 51 & 15 & 41 \\
16 & 38 & 17 & 90 \\
17 & 22 & & \\
18 & 56 & & \\
21 & 20 & & \\
24 & 66 & & \\
29 & 80 & & \\
30 & 6 & & \\
Total & 402 & & \\
\hline
\end{tabular}

Com relação ao dano, em 20 parcelas experimentais ( 4 tratamentos e 5 repetições) avaliadas sete vezes cada uma, em um total de 140 parcelas, o dano foi constatado em 60 parcelas, ou seja, em 43\% das avaliações. O número de frutos danificados em 6 árvores foi bastante baixo, e variou de um a cinco frutos, portanto menos de um fruto danificado em média por árvore. Assim o dano, apesar de baixo foi freqüente, e foi observado em parcelas, onde não ocorreu captura de moscas-das-frutas. Portanto, a constatação do dano mostrou ser um método mais preciso da presença dos insetos no pomar do que a própria avaliação das moscas-das-frutas nas armadilhas com atrativo alimentar. 
Alguns autores consideram adequada a avaliação semanal das armadilhas (Malavasi et al, 1994; Nascimento et al, 2000) e outros sugerem que esta seja feita duas vezes por semana (Orth et al, 1986). Na presente pesquisa, no experimento 2 (inverno sem chuvas), com alta captura de C. capitata, a avaliação com uma semana de exposição das armadilhas mostrou-se trabalhosa e bastante demorada, além de ocorrerem perdas de insetos por decomposição. Desta forma, optou-se pela avaliação com exposição de um dia, a qual foi mais rápida e prática, mantendo os insetos íntegros. Além disso, a captura de outros insetos, especialmente dípteros foi menor. No experimento 3 (verão chuvoso), com exposição de uma semana, houve grande captura de outros dípteros, o que tornou a avaliação trabalhosa e demorada.

Os tefritídeos adultos têm mostrado um comportamento bastante complexo e diversificado, como nas moscas do gênero Anastrepha (Aluja et al, 2001) e C. capitata (Yuval \& Hendrichs, 2001). O comportamento alimentar dos adultos pode variar de acordo com o ambiente onde estão. Assim, Anastrepha pode se alimentar em uma determinada planta e buscar frutos para oviposição em outra planta (Malavasi et al, 1983; Aluja \& Birke, 1993). Admite-se que algumas moscas da espécie $A$. fraterculus possam chegar ao pomar de laranja alimentadas, e não buscar o alimento das armadilhas, neste caso limitando a captura.

\subsection{Relação entre captura de moscas-das-frutas e o dano}

Como a espécie predominante foi C. capitata (experimento 2), correspondendo a quase $99 \%$ das moscas-das-frutas capturadas, as correlações testadas foram feitas entre a captura deste inseto e o dano, atribuído a esta espécie.

Com os resultados do experimento 3 não foi possível testar correlações entre captura e dano, pois houve poucas capturas de moscas-das-frutas e quando ocorreram, estas foram baixas. 
Houve uma relação linear e direta entre a captura, de fêmeas e machos e somente de fêmeas de $C$. capitata, e o número de frutos danificados, nas densidades de uma e duas armadilhas por hectare (Figuras 9 e 10). Nas parcelas em que ocorreu maior captura de moscas, houve maior dano 7 e 14 dias após a captura.

O número de frutos danificados, na semana de 13 a 19 de julho de 2002 , nas parcelas do tratamento com uma armadilha por hectare (Figura 9), foi dependente da captura de fêmeas e machos em 6 de julho $(r=0,99)$, e também da captura total em 13 de julho $(r=0,81)$. Do mesmo modo, houve correlação entre o dano, ocorrido entre 13 a 19 de julho, e a captura de fêmeas em 6 de julho $(r=0,99)$, e entre o dano na mesma data e a captura de 13 de julho ( $r=$ 0,86 ). Os coeficientes de determinação, e os valores de $F$, foram maiores para as correlações entre a captura de 6 de julho e o dano no período de 13 a 19 de julho. Portanto, o dano causado por C. capitata em laranja precoce foi dependente da captura dessa espécie ocorrida na semana anterior. 



Figura 9 - Relação entre captura de Ceratitis capitata e o dano em laranja cultivar Hamlin, na densidade de uma armadilha por hectare, no experimento relacionando moscas-das-frutas capturadas e frutos danificados, 7 e 14 dias após a captura. Itaju / SP, junho a agosto de 2002

De maneira semelhante, na densidade de duas armadilhas por hectare, houve correlação entre a captura de $C$. capitata e frutos de laranja danificados (Figura 10). O dano verificado entre 6 e 12 julho foi dependente tanto da captura total das moscas, fêmeas e machos $(r=0,78)$, como da captura de fêmeas em 6 de julho $(r=0,79)$. E também o dano, que ocorreu na semana seguinte, entre 13 e 19 de julho, foi correlacionado com a captura total de 6 de julho $(r=0,96)$ e de fêmeas nesta mesma data $(r=0,97)$. Os melhores ajustes 
para regressão linear (coeficientes de determinação) e teste de significância (valores de F) foram obtidos entre a captura do dia 6 de julho e o dano no período de 13 a 19 de julho.
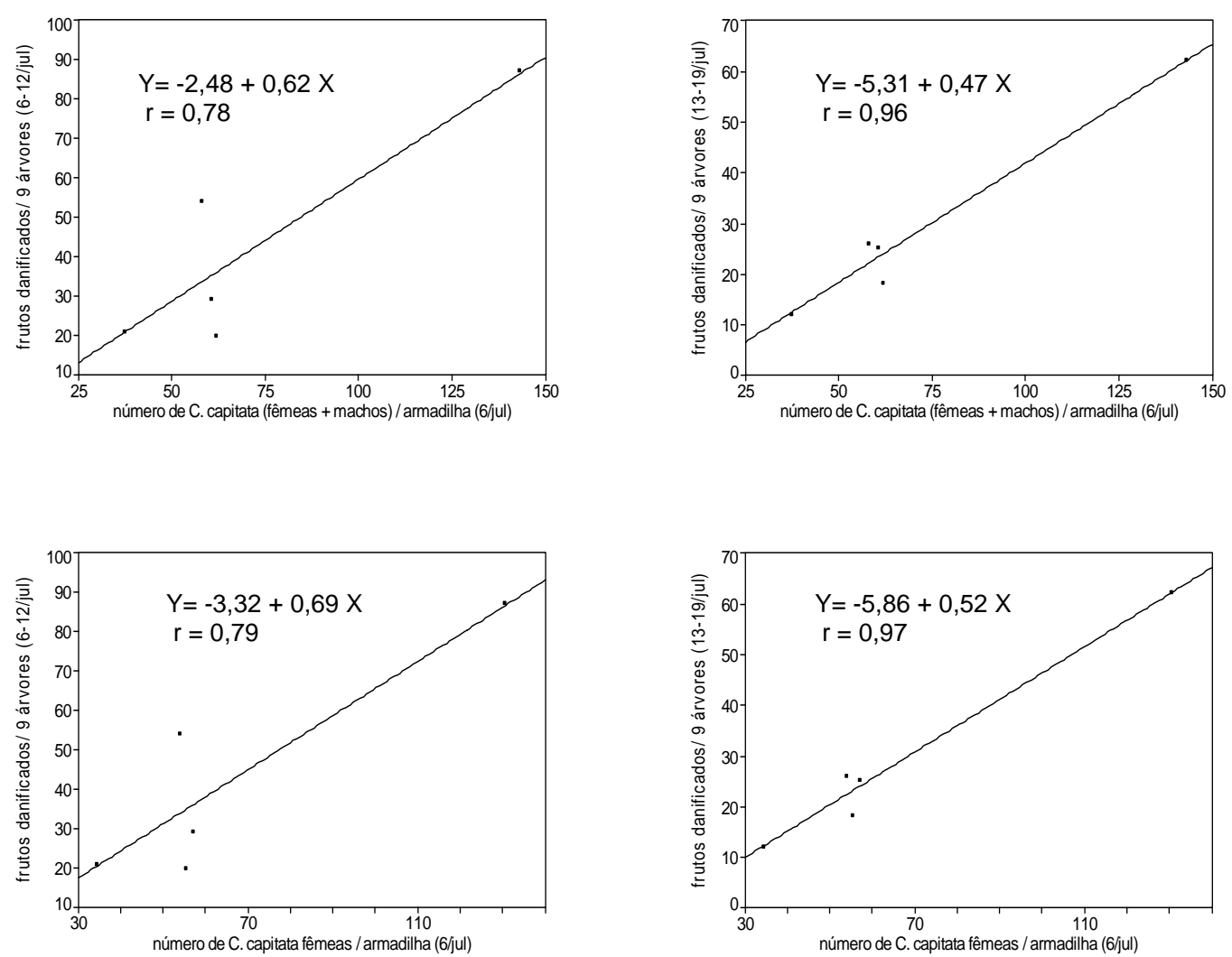

Figura 10 - Relação entre captura de Ceratitis capitata e o dano em laranja cultivar Hamlin, na densidade de duas armadilhas por hectare, no experimento relacionando moscas-das-frutas capturadas e frutos danificados, 7 e 14 dias após a captura. Itaju / SP, junho a agosto de 2002

Nas maiores densidades, de quatro e oito armadilhas por hectare, não houve correlação entre as capturas e os danos verificados nestas parcelas, na semana da captura e nas duas semanas seguintes. Assim, as maiores densidades de armadilhas estudadas, de quatro e oito armadilhas, que 
poderiam representar melhor a população de C. capitata presente no pomar, não mostraram relação com o dano observado nestas parcelas.

Não houve correlações entre a captura de C. capitata e o dano na mesma semana, em nenhuma das densidades estudadas. Existiu uma assincronia entre a captura e o dano. O período de pré-oviposição, quando ocorre a maturação sexual das fêmeas, que em C. capitata, é em média, de 10 dias, e o tempo necessário para que o sintoma no fruto seja visível, podem ser as explicações para esta diferença de tempo.

Para laranja cultivar Pêra, Fernandes (1987) observou que houve correlação entre a captura de moscas-das-frutas e a queda de frutos, com um intervalo de 35 e 49 dias entre a captura e o dano, intervalo maior do que o obtido neste trabalho, que foi de 7 e 14 dias. A queda de frutos atacados, dependendo do estágio de maturação dos frutos, pode ocorrer após vários dias da oviposição. No presente trabalho, o dano foi avaliado também na árvore, antes que o fruto caísse. Na Nigéria, em experimento de parcelas de quatro árvores, onde se avaliou o número de moscas e a porcentagem de frutos caídos em diferentes variedades, Agunloye (1987) verificou que a maior captura de $C$. capitata ocorreu na variedade de laranja onde foi constatada a menor queda de frutos, e concluiu não haver relação entre captura e dano.

Uchôa-Fernandes et al. (2003) verificaram ausência de correlação entre moscas Neosilba capturadas em armadilhas, em pomares de laranja, e larvas e adultos dessas moscas obtidas de frutos atacados, usando dados mensais, apesar das coletas terem sido feitas semanalmente.

Como são as fêmeas das moscas-das-frutas que causam o dano nos frutos, pela oviposição, a correlação entre a captura de fêmeas nas armadilhas e frutos danificados parecia ser mais provável, do que a captura total, de fêmeas e machos. No entanto, embora as fêmeas tenham predominado na captura (item 4.2) houve também correlação com a captura total. Desse modo, pode-se dispensar a separação de sexos no monitoramento de $C$. capitata. 
Autores têm citado a baixa eficácia do monitoramento de moscas-dasfrutas com atrativos alimentares, pelo limitado raio de ação, de um a dez metros (Nascimento et al, 2000; Nascimento \& Carvalho, 2000) ou pela baixa taxa de captura (Aluja, 1994), e assim a captura poderia não representar a população da área monitorada. Como no presente caso houve correlação entre a captura de C. capitata e o dano provocado por este inseto em laranja de maturação precoce, deve haver uma correlação entre a população residente na área e o dano, já que são estes os insetos responsáveis pelo dano. Pode-se inferir, portanto, pelos resultados obtidos, que existe correlação entre a população e a captura nas armadilhas com atrativos alimentares.

Adotando-se uma armadilha por hectare para o monitoramento de $C$. capitata, e admitindo-se um dano de um fruto de laranja 'Hamlin' por árvore, ou seja $Y=9$ frutos em 9 árvores, com a equação da reta $Y=-3,37+0,78 X$, obtêmse $X=16$ moscas (fêmeas e machos) por armadilha por dia. Já com a equação da reta obtida com duas armadilhas por hectare, $Y=-5,31+0,47 X$, obtêm-se $X=8$ moscas por armadilha por dia. Assim, para um dano admitido de um fruto por árvore, o nível de controle para esta praga estaria entre 8 e 16 moscas larmadilha por dia, para a variedade e a região do estudo. Como a captura tende a ser menor em períodos chuvosos, poderia ser adotado o nível de controle de 8 para esta época, e 16 para a época seca. Antes que seja recomendado, estes níveis deverão ser testados em pomares de diferentes regiões para sua validação.

Apesar de ser uma relação específica entre captura de C. capitata e frutos de laranja danificados, ocorrida na primeira quinzena de julho em uma região particular do estado de São Paulo, o nível de controle pode ser útil ao manejo deste inseto, no início das infestações e dependendo das táticas de controle adotadas. Pode acontecer da primeira captura já ser maior que este nível de controle; no entanto, se as fêmeas estiverem no período de préoviposição haverá tempo para o controle, sem que ocorram danos. 


\subsection{Dano causado pela mosca-das-frutas C. capitata em laranja precoce}

O número de frutos danificados por C. capitata não diferiu estatisticamente nas quatro primeiras semanas de avaliação, de 29 de junho a 26 de julho, porém, aumentou nas duas últimas semanas, no final de julho e início de agosto (Figura 11). O maior dano foi verificado na semana de 3 a 9 de agosto de 2002, quando o número médio de frutos danificados em 9 árvores chegou a 107,9. Com o avanço da maturação dos frutos nas parcelas do experimento, que se tornaram mais alaranjados e doces (frutos que já estavam em ponto de colheita no início do estudo) pode ter ocorrido um aumento da suscetibilidade ao dano. Frutos cítricos, em adiantado estágio de maturação, foram mais atrativos para $C$. capitata do que frutos verdes ou simplesmente maduros (Bakri, 1990 apud. Lima, 2001).

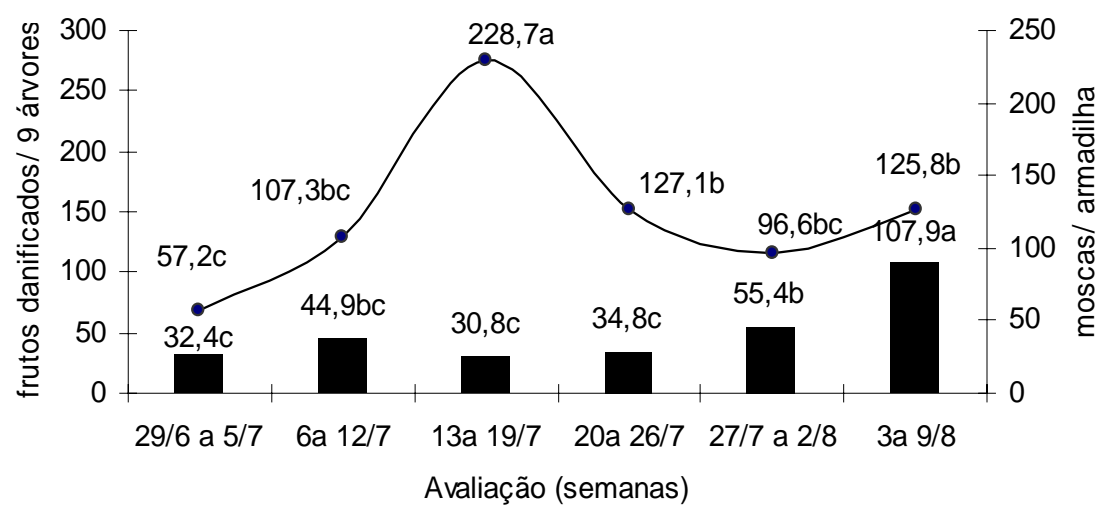

Figura 11 - Número de indivíduos capturados de Ceratitis capitata e dano causado em frutos de laranja cultivar Hamlin, no experimento de determinação da densidade de armadilhas para monitoramento e relação entre moscas-das-frutas capturadas e frutos danificados, em laranja de maturação precoce. Itaju / SP, junho a agosto de 2002. As barras representam o dano e a linha a captura de moscas 
Além disso, o avanço da colheita dos outros talhões da fazenda, onde se conduziu o experimento, poderia ter favorecido o aumento relativo da população de $C$. capitata na área experimental. A maior captura média de C.capitata ocorreu na terceira semana, quando foram coletados 228,7 insetos por armadilha; com um declínio da captura na semana seguinte (Figura 11). A segunda maior captura média do inseto se deu na última semana, com 125,8 moscas por armadilha, período em que ocorreu o maior dano.

Em experimento com a laranja cultivar Pêra, de maturação mais tardia que a 'Hamlin', Fernandes (1987), obteve o maior pico populacional de C. capitata entre 22 de julho e 4 de agosto, em Pirassununga (SP), portanto coincidente com o presente trabalho, onde a maior captura deste inseto ocorreu em 20 de julho. Porém, durante boa parte deste experimento a população foi alta, acima de 100 insetos por armadilha por dia.

No pico populacional (20/7), foram obtidas as maiores capturas individuais por armadilha. Em sete armadilhas, das 75 usadas no experimento, foram capturadas mais de 400 C. capitata por armadilha por dia, e em cinco delas a captura foi maior do que 500 moscas. Em pomar de maçã sem aplicação de inseticidas, a captura de $A$. fraterculus pode chegar a 100 insetos /armadilha /dia; no entanto, em pomares comerciais os níveis são de até 20 insetos (Kovaleski et al., 2000).

Em cada uma das parcelas experimentais, de um hectare de área útil, foram avaliadas as mesmas nove árvores durante o trabalho. Nas 6 avaliações realizadas, o número médio de frutos danificados nas árvores marcadas, variou entre as parcelas experimentais (Tabela 8). Obteve-se um dano médio de 339,6 frutos em 9 árvores, o que significa 37,7 frutos danificados por árvore no período. 
Tabela 8. Dano causado por Ceratitis capitata em frutos maduros de laranja 'Hamlin' e estimativa de perdas por hectare, em função de diferentes densidades de armadilhas para monitoramento. Itaju / SP, junho a agosto de 2002

\begin{tabular}{|c|c|c|c|c|}
\hline \multicolumn{2}{|c|}{ Parcelas } & \multicolumn{2}{|c|}{ Avaliação de dano (9 árvores) } & \multirow{2}{*}{$\begin{array}{c}\text { Estimativa/ ha } \\
\text { Kg de frutos } \\
\text { danificados }\end{array}$} \\
\hline $\begin{array}{l}\text { Armadilhas } \\
\text { /ha }\end{array}$ & repetição & $\begin{array}{l}\text { Número de frutos } \\
\text { danificados }\end{array}$ & $\begin{array}{l}\mathrm{Kg} \text { de frutos } \\
\text { danificados }\end{array}$ & \\
\hline 1 & A & 475 & $78,4^{b}$ & 3864 \\
\hline 1 & B & 235 & 38,8 & 1912 \\
\hline 1 & C & 354 & 58,4 & 2880 \\
\hline 1 & D & 209 & 34,5 & 1700 \\
\hline 1 & E & 548 & 90,4 & 4458 \\
\hline 2 & $A$ & 181 & 29,9 & 1472 \\
\hline 2 & B & 425 & 70,1 & 3457 \\
\hline 2 & C & 263 & 43,4 & 2139 \\
\hline 2 & D & 234 & 38,6 & 1903 \\
\hline 2 & E & 203 & 33,5 & 1651 \\
\hline 4 & A & 272 & 44,9 & 2213 \\
\hline 4 & B & 311 & 51,2 & 2526 \\
\hline 4 & C & 153 & 25,2 & 1245 \\
\hline 4 & D & 409 & 67,4 & 3323 \\
\hline 4 & E & 291 & 47,9 & 2363 \\
\hline 8 & A & 505 & 83,3 & 4108 \\
\hline 8 & B & 213 & 35,1 & 1729 \\
\hline 8 & C & 324 & 53,4 & 2632 \\
\hline 8 & D & 167 & 27,5 & 1354 \\
\hline 8 & E & 366 & 60,3 & 2973 \\
\hline \multicolumn{2}{|c|}{ média } & 306,7 & 50,6 & 2495,1 \\
\hline
\end{tabular}

a: 444 árvores/ ha; b: 1 fruto $=165$ gramas

Com um dano médio de 50,6 $\mathrm{Kg}$ de frutos em 9 árvores, nas 20 parcelas do estudo e uma densidade de 444 árvores por hectare, obteve-se uma perda média de $2495,1 \mathrm{Kg}$ de frutos por hectare. Entre as parcelas, as perdas variaram de 1354 a $4458 \mathrm{Kg}$ de frutos por hectare, portanto uma grande variação entre elas.

Ao longo do período do estudo, as perdas foram crescentes da primeira para a sexta semana (Figura 12), indicando que a colheita dos frutos pode evitar o aumento do dano. 


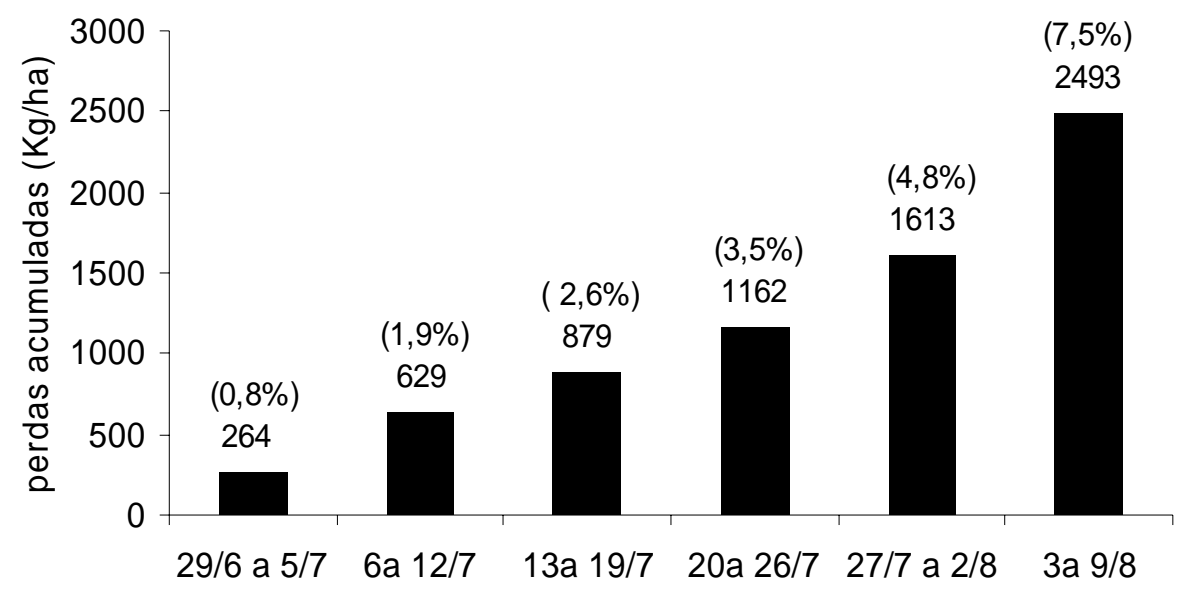

Figura 12 - Dano acumulado causado por Ceratitis capitata em frutos maduros de laranja cultivar Hamlin (porcentagem de perdas em relação ao total colhido), no experimento de determinação da densidade de armadilhas para monitoramento e relação entre moscas-das-frutas capturadas e frutos danificados. Itaju / SP, junho a agosto de 2002

A produção média dos dois talhões usados no experimento foi 30,8 toneladas de frutos por hectare, com um peso médio de 165 gramas por fruto. O rendimento industrial das frutas, fornecidos pela processadora de suco de laranja, foi $50 \%$ de suco (peso / peso) e $10^{\circ}$ Brix.

As perdas médias de aproximadamente 2,5 toneladas de frutos por hectare representam matéria-prima suficiente para se obter $192 \mathrm{~kg}$ da commoditie, suco de laranja concentrado e congelado a $65^{\circ}$ Brix, por hectare. Em termos porcentuais, as perdas causadas por C. capitata em laranja cultivar Hamlin, foram de $7,5 \%$ da produção total.

Esse valor é bem superior ao estimado por Nascimento et al. (1993), 60 mil toneladas, ou seja $0,5 \%$ da produção de laranjas de São Paulo. Tais perdas, de 2,5 toneladas por ha, somente ocorreram, nas condições experimentais, pela combinação de dois fatores; alta população da mosca C. capitata e o adiantado estágio de maturação dos frutos, cerca de dois meses após o ponto de colheita. 
No entanto, em grandes áreas de cultivo de laranja, é comum haver atraso na colheita, podendo ocorrer perdas como as referidas no presente trabalho.

\subsection{Dano causado por moscas-das-frutas em laranja tardia}

O dano observado no experimento 3 foi pequeno, com uma média de um fruto danificado por árvore durante as 6 semanas, considerando-se todas as parcelas (Figura 13).

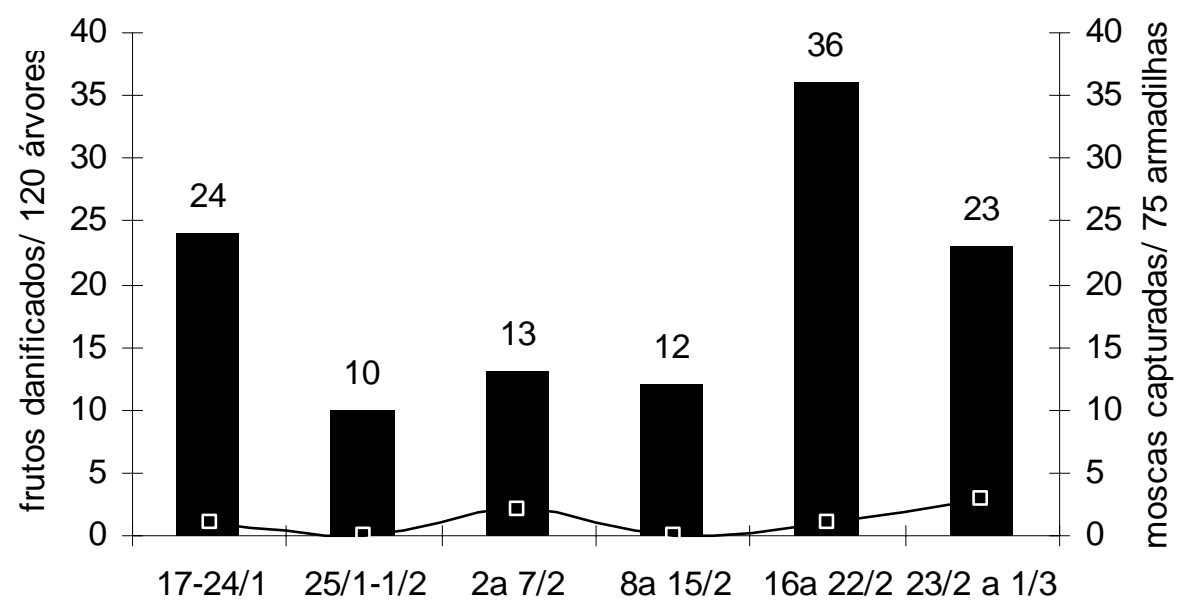

Figura 13 - Dano causado por moscas-das-frutas em frutos maduros de laranja cultivar Natal e moscas capturadas, no experimento de determinação da densidade de armadilhas para monitoramento e relação entre insetos capturados e frutos danificados. Porto Feliz/ $\mathrm{SP}$, janeiro a março de 2003. As barras representam o dano e a linha a captura de moscas

Neste caso, não houve aumento do dano com o avanço da maturação dos frutos, que se encontravam em ponto de colheita no início do experimento. As perdas foram pequenas, provavelmente pela baixa população de tefritídeos. Comparando-se os dados dos dois experimentos anteriores (item 4.6 laranja precoce e item 4.7 laranja tardia), verifica-se que o dano médio obtido em 
laranja precoce em Itaju foi de 37,7 frutos por árvore, e de apenas 1 fruto de laranja tardia em Porto Feliz.

Para áreas com baixas populações de moscas-das-frutas, atrativos mais específicos e de longo alcance, como os feromônios sexuais, ou substâncias equivalentes como o trimedlure para $C$. capitata ou o metil-eugenol para moscas do gênero Bractrocera, poderiam ser mais eficientes, pois permitem a detecção de poucos insetos na área. Mas, até que estes produtos estejam disponíveis para $A$. fraterculus, é possível utilizar-se o dano como um parâmetro indicativo da presença do inseto na área para início do controle desta praga. 


\section{CONCLUSÕES}

1. As maiores capturas de Ceratitis capitata (Wiedemann, 1824) ocorrem nas armadilhas com o atrativo protéico Milhocina ${ }^{\circledR}$ e bórax com pH inicial 8,5, aos 2, 4 e 6 dias após a sua instalação no pomar;

2. A mosca C. capitata é a espécie predominante, representando $99 \%$ das moscas-das-frutas capturadas;

3. A captura de fêmeas de C. capitata em armadilhas é maior em pomar de laranja 'Hamlin' com frutos (80\%) do que em pomar sem frutos (46\%);

4. A densidade de armadilhas utilizada, uma, duas, quatro ou oito armadilhas por hectare, não interfere na proporção de machos e fêmeas de C. capitata capturados;

5. A mosca C. capitata pode ser monitorada em áreas de altas populações com uma armadilha por hectare;

6. Há uma relação direta entre a captura de C. capitata, nas densidades de uma e duas armadilhas por hectare e os danos causados aos frutos de laranja 'Hamlin', aos 7 e 14 dias após a captura;

7. O dano causado por C. capitata em laranja de maturação precoce, em Itaju I SP, varia de 1,2 a 4,1 toneladas de frutos por hectare, com uma média de 2,5 toneladas, representando $7,5 \%$ da produção;

8. Para um dano de um fruto por árvore, o nível de controle pode ser de 8 a 16 indivíduos da espécie C. capitata capturados / armadilha / dia;

9. A presença de frutos de laranja de maturação tardia danificados, não é correlacionada com a captura de moscas-das-frutas nas armadilhas, quando há predominância de Anastrepha fraterculus (Wiedemann, 1830). 


\section{REFERÊNCIAS BIBLIOGRÁFICAS}

AGUNLOYE, O.J. Trapping and chemical control of Ceratitis capitata (Wied.) (Diptera: Tephritidae) on sweet orange (Citrus sinensis) in Nigeria. Journal of Horticultural Science, v. 62, n. 2, p. 269-271. 1987.

ALUJA, M. Bionomics and management of Anastrepha. Annual Review of Entomology, v. 39, p. 155-178. 1994.

ALUJA, M.; BIRKE, A. Habitat use by adults of Anastrepha obliqua (Diptera: Tephritidae) in a mixed mango and tropical plum orchard. Annals of the Entomological Society of America, v. 86, n. 6, p. 799-812. 1993.

ALUJA, M.; PINERO, J.; JÁCOME, I. et al. Behavior of flies in the genus Anastrepha (Trypetinae: Toxotrypanini). ). In: ALUJA, M.; NORRBOM, A. L. (Ed.). Fruit flies (Tephritidae): phylogeny and evolution of behavior. Boca Raton: CRC Press, 2001. cap. 15, p.375-406.

BATEMAN, M.A.; MORTON, T.C. The importance of ammonia in proteinaceous attractants for fruit flies (Family: Tephritidae). Australian Journal of Agricultural Research , v. 32, p. 883-903, 1981.

BRESSAN, S.; COSTA TELES, M. Recaptura de adultos marcados de Anastrepha spp. (Diptera; Tephritidae) liberados em apenas um ponto do pomar. Revista Brasileira de Entomologia, v, 35, n. 4, p. 679-684. 1991. 
CALKINS, C.O.; MALAVASI, A. Biology and control of fruit flies (Anastrepha) in tropical and temperate fruit. Revista Brasileira de Fruticultura, v,17, p. 3645, 1995.

CALKINS, C.O.; SCHROEDER, W.J.; CHAMBERS, D.L. Probability of detecting Caribbean fruit fly Anastrepha suspensa (Loew) (Diptera: Tephritidae), populations with McPhail traps. Journal of Economic Entomology, v. 77, n.1, p. 198-201, 1984.

CUNNINGHAM, R.T.; NAKAGAWA, S.; SUDA, D.Y. et al. Tephritid fruit fly trapping: liquid food baits in high and low rainfall climates. Journal of Economic Entomology, v. 71, p. 762-763, 1978.

FERNANDES, O.A. Estudos bioecológicos e avaliação de danos causados por moscas-das-frutas (Diptera: Tephritidae) em Citrus sinensis Osbeck var. 'Pêra'. Ribeirão Preto, 1987. 79 p. Dissertação (Mestrado) - Faculdade de Filosofia, Ciências e Letras de Ribeirão Preto, Universidade de São Paulo.

FERNANDES, V.G. Co-produtos da industrialização do milho. In: SIMPÓSIO DE NUTRIÇÃO ANIMAL - BOVINOS LEITEIROS, 1., Espírito Santo do Pinhal, 1998. Anais. Espírito Santo do Pinhal: Fundação Pinhalense de Ensino - CREUPI, 1999. p.117-130.

GALLO, D.; NAKANO, O.; SILVEIRA NETO, S. et al. Entomologia agrícola. Piracicaba: FEALQ, 2002. 920 p.

JIRON, L.F.; SOTO-MANITIU, J. Evaluación de campo de substancias atrayentes en la captura de Anastrepha spp. (Diptera: Tephritidae), plaga de frutales em América Tropical. III. Proteina hidrolizada y torula boratada. Revista Brasileira de Entomologia, v, 33, n. 2, p. 353-356, 1989. 
KOVALESKI, A.; SUGAYAMA, R.L.; URAMOTO, K. et al. Rio Grande do Sul. In: MALAVASI, A.; ZUCCHI, R.A. (Ed.). Moscas-das-frutas de importância no Brasil: conhecimento básico e aplicado. Ribeirão Preto: Holos, 2000. cap. 42, p.285-290.

LIMA, I.S. Semioquímicos das moscas-das-frutas. In: VILELA, E.F.; DELLA LUCIA, T.M.C. (Ed.). Feromônios de insetos: biologia, química e emprego no manejo de pragas. Ribeirão Preto: Holos, 2001. cap. 14, p. 121-126.

LOPEZ, F.D.; HERNANDEZ BECERRIL, O. Sodium borate inhibits decomposition of two protein hydrolysates attractive to the mexican fruit fly. Journal of Economic Entomology, v. 60, n. 1, p. 137-140, 1967.

MALAVASI, A. Systems approach. In: MALAVASI, A.; ZUCCHI, R.A. (Ed.). Moscas-das-frutas de importância no Brasil: conhecimento básico e aplicado. Ribeirão Preto: Holos, 2000. cap. 24, p.183-186.

MALAVASI, A.; MORGANTE, J.S. Biologia de "moscas-das-frutas" (Diptera: Tephritidae). II: Índices de infestação em diferentes hospedeiros e localidades. Revista Brasileira de Biologia, v. 40, n. 1, p. 17-24, 1980.

MALAVASI, A.; MORGANTE, J.S.; PROKOPY, R.J. Distribution and activities of Anastrepha fraterculus (Diptera: Tephritidae) flies on host and nonhost trees. Annals of the Entomological Society of America, v. 76, n. 2, p. 286-292, 1983.

MALAVASI, A.; MORGANTE; J.S.; ZUCCHI, R.A. Biologia de "moscas-dasfrutas" (Diptera: Tephritidae). I: Lista de hospedeiros e ocorrência. Revista Brasileira de Biologia, v. 40, n. 1, p. 9-16, 1980. 
MALAVASI, A.; NASCIMENTO, A.S.; CARVALHO, R.S. Moscas-das-frutas no MIP-Citros. In: DONADIO, L.C.; GRAVENA, S. (Ed.). Manejo integrado de pragas dos citros. Campinas: Fundação Cargill, 1994. p.211-231.

MORTON, T.C.; BATEMAN, M.A. Chemical studies on proteinaceous attractants for fruit flies, including the identification of volatiles constituents. Australian Journal of Agricultural Research., v. 32, p. 905-913, 1981.

NASCIMENTO, A.S.; CARVALHO, R.S. Manejo integrado de moscas-dasfrutas. In: MALAVASI, A.; ZUCCHI, R.A. (Ed.). Moscas-das-frutas de importância no Brasil: conhecimento básico e aplicado. Ribeirão Preto: Holos, 2000. cap. 22, p.169-173.

NASCIMENTO, A.S.; MORGANTE, J.S. Táticas de manejo integrado de moscas-das-frutas em citros. In: FERNANDES, O.A.; CORREIA, A.C.B.; DE BORTOLI, S.A. (Ed.). Manejo integrado de pragas e nematóides. Jaboticabal: Funep, 1990. p.127-136.

NASCIMENTO, A.S.; CARVALHO, R.S.; MALAVASI, A. Monitoramento populacional. In: MALAVASI, A.; ZUCCHI, R.A. (Ed.). Moscas-das-frutas de importância no Brasil: conhecimento básico e aplicado. Ribeirão Preto: Holos, 2000. cap. 13, p.109-112.

NASCIMENTO, A.S.; MORGANTE, J.S.; MALAVASI. A. et al. Occurence and distribution of Anastrepha in melon production areas in Brazil. In: ALUJA, M.; LIEDO, P. (Ed.). Fruit flies: biology and management. New York: SpringerVerlag, 1993. p. 39-42. 
ORTH, A.I.; RIBEIRO, L.G.; REIS FILHO, W. Manejo de pragas. In: EMPRESA CATARINENSE DE PESQUISA AGROPECUÁRIA. Manual da cultura da macieira. Florianópolis, 1986. cap. 15, p. 341-379.

PARRA, J.R.P.; ZUCCHI R.A.; SILVEIRA NETO, S. Flutuação populacional e atividade diária de vôo da mosca-do-mediterrâneo em cafeeiros "Mundo Novo". Pesquisa Agropecuária Brasileira, v.17, n.7, p. 985-992. 1982.

ROESSLER, Y. Insecticidal bait and cover sprays. In: ROBINSON, A. S.; HOOPER, G. (Ed.). Fruit flies: their biology, natural enemies and control. Amsterdan: Elsevier, 1989. cap. 9.3, p. 329-336.

SALLES, L.A. Estratificação vertical da incidência de Anastrepha fraterculus (Wied.) em fruteiras no sul do Brasil. Anais da Sociedade Entomológica do Brasil, v.24, n.3, p. 423-428, 1995.

SALLES, L.A. Efeito do envelhecimento e da decomposição do atrativo na captura de adultos de Anastrepha fraterculus (Wied.) (Diptera: Tephritidae). Revista Brasileira de Agrociência, v.5, n.2, p.147-148, 1999.

SOUZA, H.M.L.; CYTRYNOWICZ, M.; MORGANTE, J.S. et al. Occurrence of Anastrepha fraterculus (Wied.), Ceratitis capitata (Wied.) (Diptera: Tephritidae) and Silba spp. (Diptera: Lonchaeidae) eggs in oviposition bores on three host fruits. Revista Brasileira de Entomologia, v. 27, n. 3/4, p.191-195, 1983.

SOUZA FILHO, M.F.; RAGA, A.; ZUCCHI, R. São Paulo. In: MALAVASI, A.; ZUCCHI, R.A. (Ed.). Moscas-das-frutas de importância no Brasil: conhecimento básico e aplicado. Ribeirão Preto: Holos, 2000. cap. 41, p.277-283. 
UCHÔA-FERNANDES, M.A.; OLIVEIRA, I.; MOLINA, R.M.S. et al. Populational fluctuation of frugivorous flies (Diptera: Tephritoidea) in two orange groves in the state of Mato Grosso do Sul, Brazil. Neotropical Entomology, v. 32, n. 1, p. 19-25, 2003.

WHITE, I.M.; ELSON-HARRIS, M.M. Fruit flies of economic significance: their identification and bionomics. Wallingford: CAB, 1992. 601p.

YUVAL, B.; HENDRICHS, J. Behavior of flies in the genus Ceratitis (Dacinae: Ceratitidini). In: ALUJA, M.; NORRBOM, A.L. (Ed.). Fruit flies (Tephritidae): phylogeny and evolution of behavior. Boca Raton: CRC Press, 2001. cap.17, p. 429-457. 